\title{
An evidence-based appraisal of reflux disease management - the Genval Workshop Report
}

Department of Gastrointestinal Medicine, Royal Adelaide Hospital, Adelaide, Australia J Dent

Södra Hõlsocentralen, Hudiksvall, Sweden J Brun

University of Michigan Health Centre, Ann Arbor, Michigan, USA A M Fendrick

School of Medicine, Oregon Health Sciences University, Portland, Oregon, USA

M B Fennerty

Department of Pathophysiology and Gastroenterology, University of Leuven, Leuven, Belgium J Janssens

\section{Department of}

Medicine,

Northwestern

University Medical

School, Chicago,

Illinois, USA

P J Kahrilas

Department of

Medical

Gastroenterology,

Odense University

Hospital, Odense,

Denmark

K Lauritsen

Gastroenterology and Hepatology, Allegheny University of the Health Sciences, Department of Medicine, Philadelphia, Pennsylvania, USA J C Reynolds

Department of Medicine, Park Nicollet Medical Centre, St Louis Park, Minnesota, USA $M$ Shaw

Department of Medicine, The University of Sydney, The Nepean Hospital, Penrith, Australia N J Talley

Correspondence to: Professor John Dent, Department of Gastrointestinal Medicine, Royal Adelaide Hospital, North Terrace Adelaide 5000, South Australia.

\author{
J Dent, J Brun, A M Fendrick, M B Fennerty, J Janssens, P J Kahrilas, K Lauritsen, \\ J C Reynolds, M Shaw, N J Talley on behalf of the Genval Workshop Group
}

\section{Summary}

This report summarises conclusions from an evidence-based workshop which evaluated major clinical strategies for the management of the full spectrum of gastro-oesophageal reflux disease, with an emphasis on medical management.

The disease was defined by the presence of oesophageal mucosal breaks or by the occurrence of reflux induced symptoms severe enough to impair quality of life. Endoscopy negative patients were recognised as the most common subgroup; most of these patients can be diagnosed by a well structured symptom analysis. There is a consistent hierarchy of effectiveness of available initial and long term therapies that applies for all patient subgroups. Lifestyle measures were judged to be of such low efficacy that they were rejected as a primary therapy for all patient subgroups. Proton pump inhibitor therapy was considered the initial medical treatment of choice because of its clearly superior efficacy which results in the most prompt achievement of desirable outcomes at the lowest overall medical cost. It was acknowledged that most of patients require long term management and that any maintenance therapy should be chosen by step down to the regimen that is still effective, but least costly. Endoscopic monitoring of routine long term therapy was considered inappropriate, on the basis that control of symptoms is an acceptably reliable indicator of healing in patients with oesophagitis.

Laparoscopic antireflux surgery was recognised as a significant therapeutic advance, the results of which, however, depend substantially on the experience of the surgeon. There are currently no published direct comparisons of cost and efficacy outcomes of optimal medical and surgical therapies for reflux disease. To a significant degree, the choice between medical and surgical therapy should depend on informed patient preference.

Substantial advances have occurred recently in the understanding and treatment of reflux disease. By contrast, there has been relatively little research into the best strategies for capitalisation on these advances. This is a fertile field for future research.

\section{Rationale, structure and processes for the Workshop}

BACKGROUND

The diagnosis and treatment of gastrooesophageal reflux disease (GORD, reflux disease) still presents many challenges despite recent substantial advances in understanding of its pathogenesis and major improvements in therapy. The provision of both cost- and patient-effective management is especially challenging in primary care, not least because of the chronic nature of the disease. In this setting, the full spectrum of reflux disease is encountered, and initial management is usually by symptom evaluation and empirical therapy.

Patients without oesophageal erosion or ulceration (endoscopy negative reflux disease) make up the majority of those with reflux disease, but, until recently, clinical studies had concentrated on the management of patients with oesophagitis. The deficiency of information about endoscopy negative patients has previously hampered development of informed guidelines about management of the full spectrum of reflux disease. New data have now largely corrected this deficiency.

A two day international, multidisciplinary workshop was held in Genval, Belgium, in October 1997. The aim of this workshop was to develop recommendations on the management of the full spectrum of reflux disease, including endoscopy negative patients, that were based as firmly as possible on all of the available evidence at the time of the Workshop. This report therefore reflects the Workshop's emphasis on matters relevant to practical patient management in both primary and specialist care, and does not attempt to provide an exhaustive review of the field of reflux disease.

\section{WORKSHOP STRUCTURE}

The Genval Workshop involved 35 medical doctors from 16 countries. The participants were primary care physicians, specialist gastroenterologists, health economists, and surgeons who have a major involvement in managing and/or researching reflux disease. Childhood reflux disease, extra-oesophageal manifestations and refractory disease were not considered.

The Workshop content was divided into four sequential segments. Each of the first three segments involved, in turn, plenary state-ofthe-art lectures, division of the participants into three concurrent discussion subgroups, then a plenary discussion and voting session. The fourth segment was a plenary session that considered strategic issues. Statements were prepared which focused on specific issues most relevant to non-surgical management. Each statement was then assigned to a participant in

Abbreviations used in this report: GORD, gastro-oesophageal reflux disease; PPI, proton pump inhibitor; SF-36, short form 36; PGWB, psychological general well being; GSRS, gastrointestinal symptom rating scale; $\mathrm{H}_{2} \mathrm{RA}, \mathrm{H}_{2}$ receptor antagonist. 
Table 1 Levels of support and nature of evidence used in voting on statements at the Genval Workshop

\begin{tabular}{ll}
\hline Category & Level of support \\
\hline A & Accept completely \\
B & Accept with some reservation \\
C & Accept with major reservation \\
D & Reject with reservation \\
E & Reject completely \\
Category & Nature of the evidence \\
A & Well designed and appropriately controlled trials \\
B & Well designed cohort or case controlled studies \\
C & Case reports or flawed clinical trials \\
D & My own clinical experience \\
E & There is not sufficient evidence available to form \\
& an opinion \\
\hline
\end{tabular}

advance of the Workshop who prepared and then presented a review of the relevant data to one of the three concurrent discussion subgroups. The statement was then discussed and voted on anonymously by the subgroup (table 1). At plenary sessions, subgroups reported their discussions and the outcome of their voting, further discussion occurred as necessary, and then the full Workshop voted anonymously (table 1), this time electronically.

The time available for the Workshop did not make it possible for adequate consideration of management strategies. The authors of this report, who were the core group responsible for the planning of the Workshop, met after the Workshop to evaluate management strategies in the light of the Workshop outcomes. The decision pathways given in this report are therefore primarily the product of this core group.

PROCESS, FORMAT AND REPORTING OF VOTING Participants were instructed to vote on the basis of what they believed to be the best medical management, without regard to cost, except when statements specifically included cost considerations. The template used is given in table 1 .

The outcome of voting from plenary sessions is given in this report, together with the relevant statement, which is numbered in bold and printed in italics. The wording of statements has been left unedited to ensure that the report reflects faithfully what was voted upon.

In the interests of brevity, the full outcome of the Workshop voting is not described. Acceptance $(>50 \%$ voting for categories $\mathrm{A}, \mathrm{B}$ or $\mathrm{C}$ level of support) or rejection ( $>50 \%$ voting for categories D or E) is indicated in bold and underlined before each statement, together with the median vote on the level of support, from A to E.

A view of the participants on a statement was deemed to be representative if $<20 \%$ of participants voted category $\mathrm{E}$ on the nature of evidence (insufficient evidence). When statements did not meet this criterion, this is noted in the commentary.

The median vote on the nature of evidence, from $\mathrm{A}$ to $\mathrm{E}$, is given in bold and underlined at the end of the statement text. The divisions used for the nature of evidence cannot describe each and every different type of evidence available. Category C, for example, was used for indirect evidence from studies not designed to address directly the issue in the statement.

Each statement is followed by a summary of major points raised during discussion at the Workshop, and relevant references. Additionally, commentary and opinion from the subsequent meeting of the Workshop core group has been included in the text, and identified as originating from the core group.

The report is presented in two sections. Firstly, the statements which address key considerations in the management of reflux disease are presented and discussed. Secondly, the evidence presented is translated into clinical strategy, together with algorithms of proposed decision pathways in patient management (figs 1-4).

\section{Key considerations in the management of reflux disease}

DEFINITIONS OF REFLUX DISEASE

1 Accepted - B: The term "gastro-oesophageal reflux disease" (GORD, reflux disease) should be used to include all individuals who are exposed to the risk of physical complications from gastrooesophageal reflux, or who experience clinically significant impairment of health related well being (quality of life) due to reflux related symptoms, after adequate reassurance of the benign nature of their symptoms. Evidence - B. ${ }^{1-4}$ Physical complications include any of the local oesophageal complications of oesophagitis, or asthma, aspiration pneumonia and laryngitis attributable to reflux. Concern that minor reflux symptoms could possibly be due to a life threatening disorder frequently results in impairment of quality of life (see statement 12), and it is important that this effect should be distinguished from the direct impact of symptoms (see statements 10 and 11).

2 Accepted - A: The term "endoscopy negative reflux disease" should be reserved for individuals who satisfy the definition of gastro-oesophageal reflux disease, but who do not have either Barrett's oesophagus or definite endoscopic oesophageal mucosal breaks (oesophageal mucosal erosion or ulceration). Evidence - A. Mucosal breaks are a clear indication of the presence of oesophagitis, but so called "minor changes" (erythema, oedema, friability) are not (see statement 25). ${ }^{6}$

Core group: The lack of an explicit definition of GORD has been a problem to date, and given the acceptance of these pragmatic definitions at the Workshop they were subsequently used throughout the Workshop. Discussions of oesophagitis are based on the Los Angeles classification system for the endoscopic assessment of oesophagitis (table 2). ${ }^{78}$

PATHOGENESIS AND NATURAL HISTORY

3 Accepted - A: The dominant mechanism of symptom production in reflux disease is by contact of the oesophageal mucosa with acid and pepsin. Evidence - B..$^{9-12}$

4 Accepted - A: In the majority of people with reflux disease, there is abnormally prolonged exposure of the distal oesophagus to acid and pepsin. Evidence - A. ${ }^{8-14}$ 
Table 2 The Los Angeles Classification System for the endoscopic assessment of oesophagitis

\begin{tabular}{ll}
\hline Grade & Definition \\
\hline A & $\begin{array}{c}\text { One or more mucosal breaks no longer than } 5 \mathrm{~mm}, \\
\text { none of which extends between the tops of the } \\
\text { mucosal folds }\end{array}$ \\
B $\quad \begin{array}{l}\text { One or more mucosal breaks more than } 5 \mathrm{~mm} \text { long, } \\
\text { none of which extends between the tops of two } \\
\text { mucosal folds }\end{array}$ \\
C Mucosal breaks that extend between the tops of two \\
or more mucosal folds, but which involve less \\
than $75 \%$ of the oesophageal circumference \\
Mucosal breaks which involve at least $75 \%$ of the \\
oesophageal circumference
\end{tabular}

This is the agreed final version of the classification. ${ }^{8}$ Note that the definition of grades $\mathrm{C}$ and $\mathrm{D}$ differs slightly from the published proposed Los Angeles classification. ${ }^{7}$

5 Accepted - A: In a minority of people with reflux disease, normal levels of reflux of acid and pepsin trigger reflux-induced symptoms. Evidence - B. ${ }^{15}$

Core group: These statements were voted on, but not discussed. Oesophageal $\mathrm{pH}$ monitoring shows, on average, less acid exposure in endoscopy negative patients than in those with oesophagitis, but still more than in healthy controls. It should not be assumed that the mix of pathogenetic factors is the same in endoscopy negative reflux disease as in reflux oesophagitis, as increased oesophageal sensitivity may play a more prominent role in endoscopy negative reflux disease. ${ }^{16}$

6 Accepted - A: Lifestyle factors are not the dominant factor in pathogenesis of reflux oesophagitis. Evidence - C. ${ }^{17-19}$ This is contrary to commonly held opinion.

7 Accepted - A: There is insufficient objective evidence to determine the importance of lifestyle factors in the pathogenesis of endoscopy negative reflux disease. ${ }^{17-22}$ More research is needed into the impacts of obesity, dietary fat intake and other lifestyle factors on the pathogenesis of endoscopy negative reflux disease.

8 Accepted - B: Endoscopy negative reflux disease does not progress to oesophagitis, during a 10 year follow up period. Evidence - C. ${ }^{23-25}$

Core group: Some initially endoscopy negative patients have Los Angeles grade A oesophagitis intermittently.

9 Accepted - B: The severity grade of oesophagitis does not worsen during a 10 year follow up period. Evidence - C. Most longitudinal studies of oesophagitis severity are of less than 10 years' duration. ${ }^{23-27}$ All are difficult to interpret because of treatment effects and imprecise and inconsistent reporting of endoscopic findings. Progression of oesophagitis severity has been reported in a minority of cases, though if patients receive sufficient treatment to control symptoms, they are unlikely to experience such a progression.

Core group: The natural history of Los Angeles grades $\mathrm{A}$ and $\mathrm{B}$ oesophagitis may differ from grades $\mathrm{C}$ and $\mathrm{D}{ }^{28}$

IMPACT OF THE DISEASE ON THE PATIENT

10 Accepted - B: Health related well being is impaired in proportion to the frequency of heartburn. Evidence - B. ${ }^{41629-34}$ As heartburn is the most prevalent symptom of reflux disease, it has the most important impact of all symptoms. Recent data indicate that heartburn causes a similar significant impairment of health related well being irrespective of whether or not oesophagitis is present. These studies have assessed health related well being using the Short Form $36(\mathrm{SF}-36)^{16}{ }^{34}$ or the Psychological General Well Being (PGWB) index which are general health profiles rather than being disease specific, and the Gastrointestinal Symptom Rating Scale (GSRS) which has a reflux disease specific dimension. 11 Accepted - B: Reflux disease is likely to be present when heartburn occurs on two or more days a week, on the basis of the negative impact of this symptom frequency on health related well being (quality of life). Evidence - C. ${ }^{29-32}$ The vote was not fully representative as $24 \%$ considered the evidence to be insufficient to define the severity of reflux induced symptoms by frequency alone. Many people who experience infrequent reflux induced symptoms should not necessarily be considered to have reflux disease, at least on the basis of the impact of symptoms on well being. The statement may serve as a practical guideline for the physician, based on quality of life studies in reflux disease, with the caveat that less frequent symptoms do not preclude disease. Thus in figure 1, individuals with reflux induced symptoms are divided into those with and without reflux disease.

Core group: Quality of life data in reflux disease, and their calibration relative to the impact of other diseases, are limited. Several large studies have been published very recently (see commentary on statement 12).

12 Accepted - B: Concern about reflux induced symptoms being due to a life threatening problem such as cancer is common amongst patients who have not been endoscoped, and causes impairment of health related well being which is additive to any impairment due to the direct impact of symptoms. Evidence - C. ${ }^{5}{ }^{16} 33$ 35-39

Core group: This matter has only been investigated recently in unselected patients undergoing upper gastrointestinal endoscopy. ${ }^{39}$ If concern about the cause of symptoms is a major motivation for consultation, reassurance may be all that is required for reflux induced symptoms (see statement 1 ), though very anxious patients will not be reassured for any length of time even by endoscopy. ${ }^{39}$ There may be differences in the degree to which anxiety is an important factor between those seen in primary care and those referred for investigation as anxiety will bias for referral. In a group of referred patients, quality of life has been shown to improve following endoscopy, presumably reflecting relief of concern over the cause of symptoms. ${ }^{39} 41$

HEARTBURN AS A PIVOTAL SYMPTOM FOR THE DIAGNOSIS OF REFLUX DISEASE

13 Accepted - C: When heartburn is a major or sole symptom, gastro-oesophageal reflux is the cause in at least $75 \%$ of individuals. Evidence D. ${ }^{42}$ Evidence-based documentation of the positive predictive value of heartburn for reflux disease is lacking, in part because of the lack of an acceptable gold standard for the diagnosis of reflux disease in the absence of oesophagitis 
(see statements 30-32). The single study published to date ${ }^{43}$ is methodologically flawed because the patient population was selected, the structure of symptom measurement was not described and, in particular, because oesophageal acid exposure was relied on as the gold standard for the diagnosis of reflux disease (see statement 30). The acceptance of the statement indicates the consistency of indirect evidence and clinical experience.

14 Accepted - B: Heartburn is the most common symptom of reflux disease, occurring in at least $75 \%$ of patients. Evidence - C. ${ }^{43}$ Consistently strong clinical experience was judged to provide the major support for this statement which had an unusually wide range of voting on the nature of the evidence. Studies of endoscopy negative reflux disease are unhelpful as they have selected patients by the presence of heartburn. ${ }^{44-46}$

15 Accepted - A: Heartburn that occurs in the absence of definite endoscopic reflux oesophagitis is most likely due to gastro-oesophageal reflux. Evidence - B..$^{154647}$

Core group: Oesophageal pH monitoring studies in endoscopy negative reflux disease support this strategically important statement. 16 Accepted - A: The word "heartburn" is interpreted unreliably by patients. Evidence B. ${ }^{48}$ The careful assessment of patient history, which is important in the diagnosis of reflux disease, can be confounded by misinterpretation of the word heartburn. Cultural variations in recognition and translation of the word have been identified in a formal study as well as by clinical experience. Description of heartburn as "a burning feeling rising from the stomach or lower chest up towards the neck" has been found to identify recognise more patients with heartburn than use of the word per se. ${ }^{49} 50$

OTHER SYMPTOM PATTERNS IN REFLUX DISEASE, AND RELIEVING AND EXACERBATING FACTORS 17 Accepted - B: True dyspeptic symptoms (according to the Rome Criteria) can be produced by gastro-oesophageal reflux. Evidence -B..$^{47}$ The Rome criteria specifically exclude heartburn from the definition of dyspepsia. Oesophageal $\mathrm{pH}$ monitoring studies, however, suggest that in a minority of patients true dyspepsia results from gastro-oesophageal reflux. 18 Accepted - B: In the absence of chronic peptic ulcer and definite reflux oesophagitis, upper abdominal/lower retrosternal symptoms that are consistently relieved by antacid are most likely to be due to reflux disease. Evidence - C. ${ }^{42} 432$ Dyspepsia and/or heartburn occurring in patients who have a normal endoscopy may be related to oesophageal sensitivity to acid, ulceration, motility disorders, medication, and psychological disorders. Of these diagnoses, only endoscopy negative reflux disease would be expected to respond to antacids more often than placebo.

19 Accepted - B: Simple, self administered symptom questionnaires can substantially facilitate the diagnosis of reflux disease. Evidence B. ${ }^{4852}$ Questionnaires which define symptoms (see statement 16) and evaluate relieving/ exacerbating factors were judged to be promising for increasing the efficiency and sensitivity of symptom evaluation, especially in primary care. Experience with these questionnaires is limited, and they have not been fully validated or specifically adapted for use in routine clinical practice.

Core group: A brief upper abdominal symptom questionnaire is needed in clinical practice in which evaluation of the patterns of reflux induced symptoms would be an important element. A well designed questionnaire should be an efficient method for reliable exploitation of the diagnostic value of symptoms and would complement educational measures that make doctors more aware of the usefulness of analysis of patterns of upper abdominal symptoms for recognition of patients with reflux disease. 20 Accepted - B: Reflux symptoms occur predominantly after food intake. Evidence - B. Symptom and $\mathrm{pH}$ monitoring studies have shown that symptoms are most frequent after meals, when most reflux occurs. ${ }^{53-55}$

21 Accepted - B: Reflux symptoms disturb sleep in only a minority of people with reflux disease. Evidence - B. ${ }^{56}$ Nocturnal reflux is usually only abnormally increased in a relatively small minority of patients, mainly amongst those with Los Angeles grades C and D oesophagitis. ${ }^{53} 54$

22 Accepted - B: The intensity and the frequency of reflux induced symptoms are poor predictors of the presence or severity of endoscopic mucosal breaks (erosion or ulceration). Evidence - B. ${ }^{43-46}$ 58-59 Convincing data were reviewed in support of this.

Core group: This is an important clinical point which is not widely appreciated.

\section{ROLE OF ENDOSCOPY}

23 Accepted - A: Endoscopic oesophageal mucosal breaks (erosion or ulceration) are absent in more than $50 \%$ of individuals who have had heartburn two or more times a week for six months. Evidence - B. ${ }^{44-4657}$ Data from large clinical trials which have enrolled patients from primary care support this.

Core group: Reflux disease should not be discarded as a diagnosis on the basis of a negative endoscopy. The low sensitivity of endoscopy for diagnosing reflux disease is currently not widely recognised.

24 Accepted - B: Amongst untreated patients presenting with reflux disease in primary care, there is a low (5\% or less) prevalence of oesophagitis of a severity that is associated with any significant risk from local complications. Evidence - B. ${ }^{60-63}$ Local complications were defined as development of stricture, Barrett's oesophagus or deep ulceration. The relatively high prevalence of severe oesophagitis (Los Angeles grades C and D) at tertiary centres reflects filtration by referral. Community and primary care studies support the statement, except for an American study in which $16 \%$ of patients had severe oesophagitis. $^{63}$

Core group: This statement assumes that Los Angeles grades A and B oesophagitis has a low risk of local complications (see aims of management). 
25 Accepted - B: The recognition of minor endoscopic mucosal changes (erythema, oedema, friability) attributed to reflux disease is so unreliable that these findings are of no use in diagnosis of reflux oesophagitis. Evidence - B.$^{6{ }^{6465}}$ These changes are not recognised to an acceptable level of reproducibility, either by individual observers or between observers. ${ }^{6}$ Therefore, any patient who is considered to have such changes should be defined as having endoscopy negative disease, and the changes not commented on as to do so suggests that such minimal changes are of diagnostic value.

Core group: This is an especially important statement. Reliance on minor endoscopic changes confounds a substantial number of clinical studies and will frequently misdirect management.

26 Accepted - C: Inexact description of the endoscopic appearance of the oesophageal mucosa frequently impairs the utility of endoscopy as a tool for management of reflux disease. Evidence - D. ${ }^{7}$ The vote was not fully representative as $36 \%$ considered the evidence to be insufficient.

Core group: The adequacy of reporting seems to vary widely. Reports such as mild oesophagitis are unacceptably non-specific as minor endoscopic mucosal changes (of no diagnostic value: see statement 25) may be grouped with Los Angeles grades A and B oesophagitis (of high diagnostic value) under this heading. Precise grades, according to a documented grading system, should be given in endoscopy reports to ensure more specific understanding of what the endoscopist saw. Members of the core group differed in their opinions as to how detailed the description of endoscopic findings should be.

27 Accepted - A: Endoscopic oesophageal mucosal biopsy has no role in the routine diagnosis of endoscopy negative reflux disease. Evidence C. ${ }^{66-68}$ The support for this was based on the experience in adults which has shown poor correlation of biopsy with $\mathrm{pH}$ monitoring findings and typical symptoms responsive to treatment. The high cost of biopsy was an additional consideration.

BARRETT'S OESOPHAGUS AND SHORT SEGMENT COLUMNAR METAPLASIA

28 Accepted - A: Endoscopic biopsy is the only method for diagnosis of Barrett's oesophagus that has acceptable sensitivity for patient management. Evidence - B..$^{69}{ }^{70}$ In reality this contributes to the dilemma of how to select patients for endoscopy (see statements 22-24 and 55).

29 Rejected - E: Current data indicate that Barrett's metaplasia of less than $3 \mathrm{~cm}$ (goblet cells in tubular oesophagus) is of no clinical significance. Evidence - C. ${ }^{71-74}$ The vote was not fully representative as $28 \%$ considered the evidence to be insufficient. Indirect data suggest that the finding of columnar metaplasia of less than 3 $\mathrm{cm}$ may indicate an increased risk for oesophageal carcinoma. The existence of case reports of development of dysplasia and carcinoma in short segments of metaplasia explains why the statement was rejected, though the actual risk is unknown. The required long term follow up studies do not exist, and reliable detection of short segment columnar metaplasia, incorrectly named short segment Barrett's oesophagus, has technical problems. The management of short segment metaplasia is an important unresolved issue.

Core group: Primary care doctors can probably only be guided by the opinion (or prejudice) of a specialist gastroenterologist on how to react to this finding.

PLACE OF $\mathrm{pH}$ MONITORING AND OTHER INVESTIGATIONS

30 Accepted - A: Twenty four hour oesophageal acid exposure is not sufficiently sensitive for it to serve as a diagnostic gold standard for reflux

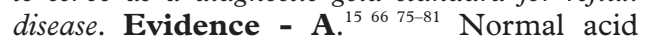
exposure values are recorded in up to a quarter of patients with otherwise typical reflux oesophagitis, and in about one third of patients with endoscopy negative reflux disease. The classification of normal/abnormal acid exposure changes in a minority of patients when they are studied a second time..$^{80-81}$

Core group: The substantial limitation of the diagnostic sensitivity of oesophageal acid exposure values is not widely recognised.

31 Accepted - A: Evaluation of the association of symptoms with reflux episodes gives a clinically valuable gain in the sensitivity of $\mathrm{pH}$ monitoring for diagnosis of reflux disease. Evidence B. ${ }^{10-12} 47$

Core group: Oesophageal pH monitors include a button which, when it is pushed, marks the time on the $\mathrm{pH}$ tracing. Thus, if patients are instructed to push the button when they experience symptoms, it is possible to determine the relation of symptoms to acid reflux.

32 Accepted - C: The practical difficulties of evaluation of symptom association mean that it cannot be used effectively as a gold standard for the diagnosis of reflux disease in groups of patients. Evidence - C. ${ }^{10-12} 82-84$

Though the clinical gain of studying symptom association is clear, the most appropriate computer software is not widely available and the methodology may still not be developed sufficiently. There is also lack of agreement on how to correlate reflux episodes and symptoms. Opinion was divided as to how reliably patients, as a group, are able to use a symptom event marker during ambulatory $\mathrm{pH}$ recordings.

33 Accepted - A: Hiatus hernia can not be used as a firm criterion for the diagnosis of reflux disease, as it is not consistently associated with this problem. Evidence - B ${ }^{85-88}$

34 Accepted - A: Fluoroscopic demonstration of reflux episodes is of no value for the diagnosis of reflux disease. Evidence - B. ${ }^{89}$ Careful performance of standardised physical stress manoeuvres during barium fluoroscopy is of minor diagnostic value, but this approach is rarely used during routine diagnostic studies, and stress manoeuvres are difficult to standardise.

DRUG THERAPY AS AN AID TO DIAGNOSIS

35 Accepted - B: Proton pump inhibitors are the agents of choice for a diagnostic trial. Evidence - C. ${ }^{46^{90-93}}$ Recent data indicate that a trial of drug therapy is useful in testing a 
provisional diagnosis of reflux disease, both before endoscopy, or afterwards when it is negative. However, only a single, technically limited study has compared use of ranitidine with omeprazole for this purpose. ${ }^{90}$

Core group: The support for this is largely derived from the convincing superiority of proton pump inhibitors in producing symptom relief compared with other medical treatments. ${ }^{94}$ See statement 56 for further discussion of the use of a trial of therapy.

36 Accepted - B: Trials of proton pump inhibitor therapy are most sensitive for the diagnosis of reflux disease when a high dose is used (e.g. omeprazole 20 or $40 \mathrm{mg}$ twice daily). Evidence B. ${ }^{90}$ This is compared with standard proton pump inhibitor doses (e.g. omeprazole $20 \mathrm{mg}$ once daily). Patchy supportive data come from several studies with omeprazole. ${ }^{91} 929596$

Core group: Voting was probably also influenced by randomised clinical trials and cohort studies which show therapeutic gain from double the standard daily proton pump inhibitor dose. $^{9697}$

TREATMENT WITH NON-DRUG MEASURES AND ANTACIDS

37 Accepted - B: People who have reflux disease are frequently led to believe that they should be able to cure themselves by correction of an inappropriate lifestyle. Evidence - D. ${ }^{98}$ As there are no systematic studies on this, the statement could only be viewed as an opinion. Voting ranged widely for both acceptance/rejection and the nature of the available evidence.

Core group: When read in conjunction with statements 39-45, the voting suggests that there is currently a significant overestimation of the possibility of patients deriving adequate relief from alteration of lifestyle factors.

38 Accepted - B: The time patterning of oesophageal acid exposure indicates that bed head elevation is an illogical therapy in the majority of people with reflux disease. Evidence - B. ${ }^{53}$ 54 99-101 Most reflux is postprandial (see statements 20 and 21). A small subgroup, identifiable by nocturnal symptoms, major nocturnal acid exposure or severe oesophagitis, ${ }^{53}$ may benefit from bed head elevation.

Core group: The demonstrated impact of bed head elevation on nocturnal acid exposure is small when compared with proton pump inhibitor treatment. ${ }^{9699100}$

39 Accepted - B: Cessation of smoking has minimal if any benefit for the management of endoscopy negative reflux disease. Evidence C. ${ }^{20}{ }^{2198}$ Comment as for statement 41 .

40 Accepted - A: The avoidance of particular foods and/or alcoholic drinks which provoke reflux induced symptoms can give a therapeutically useful reduction of these symptoms. Evidence - C.

Core group: The high level of support for this statement is unique amongst life style measures considered at the Workshop. Support comes from $\mathrm{pH}$ monitoring studies ${ }^{102-104}$ and clinical experience.

41 Accepted - B: Cessation of smoking has minimal if any benefit for the management of reflux oesophagitis. Evidence - C.
Core group: Physiological and $\mathrm{pH}$ monitoring studies are somewhat conflicting ${ }^{2021}$ and there are no rigorous intervention studies.

42 Accepted - B: The avoidance of particular foods and/or alcoholic drinks which provoke refluxinduced symptoms is of no value for healing of oesophagitis. Evidence - C.

Core group: There are no data which indicate a positive effect on oesophagitis, despite statement 40 .

43 Accepted - B: Lifestyle measures and antacids are of minimal, if any, benefit for initial and long term therapy of patients with reflux oesophagitis. Evidence - C. ${ }^{17} 98{ }^{101}{ }^{105-107}$ There is a remarkable lack of data in this area.

Core group: Comment as for statements 39-42.

44 Rejected - D: In endoscopy negative reflux disease, lifestyle measures and antacids are sufficiently effective to justify a trial of their use as initial therapy. Evidence - C. ${ }^{17} 98101{ }^{107}$ The voting reflects lack of data, the view that lifestyle measures can impair patient quality of life, and the fact that many patients seeking medical advice have already tried lifestyle measures and antacids and found them ineffective.

Core group: Despite the above, it may be of value to check that individual patients are not exposing themselves to potentially important lifestyle factors.

45 Rejected - D: In endoscopy negative reflux disease, lifestyle measures and antacids are sufficiently effective to justify a trial of their use as long term therapy. Evidence - C. ${ }^{17} 98101$ The same considerations apply as for the previous statement.

Core group: This vote was perhaps too globally negative. See statement 40 .

EFFICACY OF DRUG TREATMENT

In this section, efficacy is defined as both symptom response and healing of oesophagitis when applicable.

46 Accepted - A: For initial and maintenance therapy of reflux oesophagitis there is an ascending level of efficacy from either $\mathrm{H}_{2}$ receptor antagonist or cisapride, to a combination of an $\mathrm{H}_{2}$ receptor antagonist with cisapride, to a proton pump inhibitor. Evidence - A..$^{94} 109110$ The relative efficacies of drug therapies in reflux oesophagitis are well established. With respect to the efficacy of a combination of an $\mathrm{H}_{2}$ receptor antagonist with cisapride, the one study that makes a valid comparison with omeprazole failed to show a statistically significant difference between these two options. However, the subgroups were relatively small and omeprazole was numerically substantially superior. ${ }^{109}$

Core group: Voting on this statement does not strictly match the available objective evidence.

47 Accepted - A: For initial therapy of endoscopy negative reflux disease there is an ascending level of efficacy from either $\mathrm{H}_{2}$ receptor antagonist or cisapride, to a proton pump inhibitor. Evidence - B. Recently, a series of large randomised, controlled clinical trials has demonstrated that the hierarchy of efficacy in endoscopy negative reflux disease is the same as in reflux oesophagitis, on the basis of comparisons of 


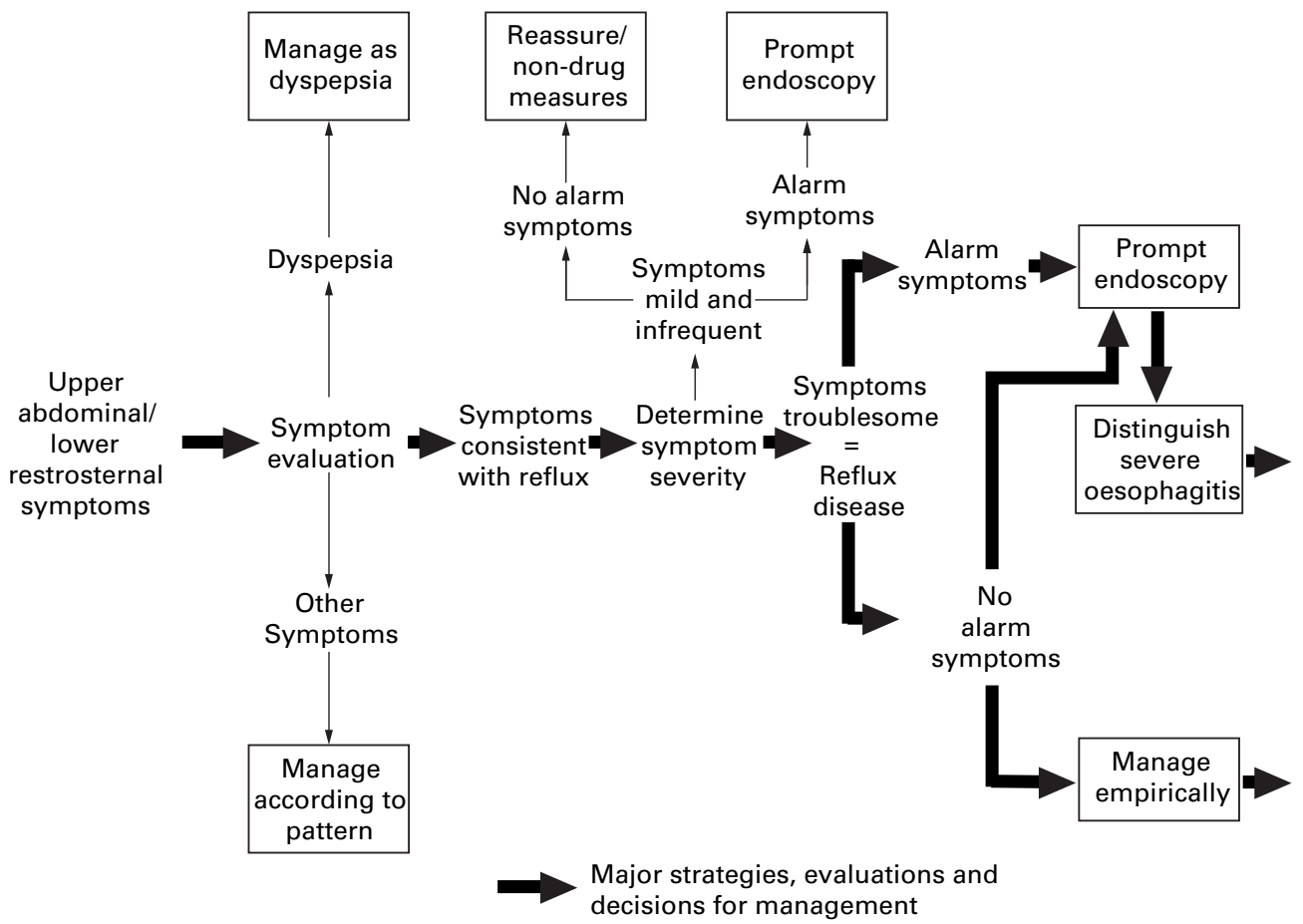

Figure 1 Initial pathways for management of upper abdominal/lower retrosternal symptoms. Patients with reflux disease should be distinguished from individuals who experience mild, infrequent symptoms as a result of gastro-oesophageal reflux (statements 1, 10,11, and 12). In patients with reflux disease who do not have alarm symptoms there is a lack of data on the relative merits of the strategies of prompt endoscopy, or initial empirical therapy. The Workshop favoured initial endoscopy as most appropriate. The core group was less convinced of this strategy (statement 54). The choice between prompt endoscopy and empirical therapy will, in practice, depend on individual patient factors, as well as access to, and cost of endoscopy (statements 12, 53, 54, and 55).

omeprazole with placebo, ranitidine and cisapride. ${ }^{44-46} 57111$

48 Accepted - A: The efficacies of standard dose $\mathrm{H}_{2}$ receptor antagonists and cisapride are essentially equivalent for both erosive oesophagitis and endoscopy negative reflux disease patients. Evidence - A..$^{112113}$ It was suggested that cisapride may be of greatest benefit for patients with slow gastric emptying, but agreed that there are no data to support this.

Core group: Patients with Los Angeles grades $\mathrm{C}$ and $\mathrm{D}$ oesophagitis should be excluded from this statement (see later).

49 Accepted - B: There are minimal or no gains in efficacy from doubling of the dose of $\mathrm{H}_{2}$ receptor antagonist therapy. Evidence A. ${ }^{94}{ }^{114-117}$ It was clarified that this was doubling of the "standard ulcer healing dose". Dose frequency may have marginal effects.

Core group: The data are limited to patients with oesophagitis.

50 Accepted - A: A clear dose response relation has not been established for therapy of reflux oesophagitis with cisapride. Evidence B. ${ }^{112}{ }^{118-120}$ Data are limited and the few studies involve small patient numbers.

51 Accepted - A: Maintenance combination therapy with cisapride and an $\mathrm{H}_{2}$ receptor antagonist is more efficacious than monotherapy with $\mathrm{H}_{2}$ receptor antagonist or cisapride alone. Evidence A. ${ }^{109}$ Data on this are relatively limited but convincing.

52 Accepted - A: Maintenance therapy with either cisapride or $\mathrm{H}_{2}$ receptor antagonist is significantly less effective than therapy with a proton pump inhibitor. Evidence - A. ${ }^{109121}$ Compara- tive data are limited to oesophagitis in one study, but are convincing.

\section{Translation of evidence into clinical strategy}

The statements discussed at Genval that were primarily focused on clinical strategies are reported on below. The evaluation of these statements relied heavily on the discussions that have been summarised above. In a follow up meeting, the core group discussed all of the material generated at the Workshop, and evaluated decision pathways for the management of reflux disease which are summarised in figures $1-5$. This section of the report is therefore derived from a combination of discussions at the Workshop itself, and from the subsequent core group discussion.

EFFECTIVE USE OF SYMPTOM ANALYSIS FOR

INITIAL ASSESSMENT

Discussion and voting on statements 13-22

above emphasised the central importance of symptom analysis for initial management (fig 1). Participants concluded that symptom analysis was a very practical and inexpensive approach to diagnosis which identified most endoscopy negative patients as well as those with oesophagitis.

Initial symptom evaluation was also considered to be important for determining whether reflux induced symptoms were sufficiently severe to justify the diagnosis of reflux disease (statements 1,10 and 11 ; fig 1 ). It was recognised, though, that symptom assessment 


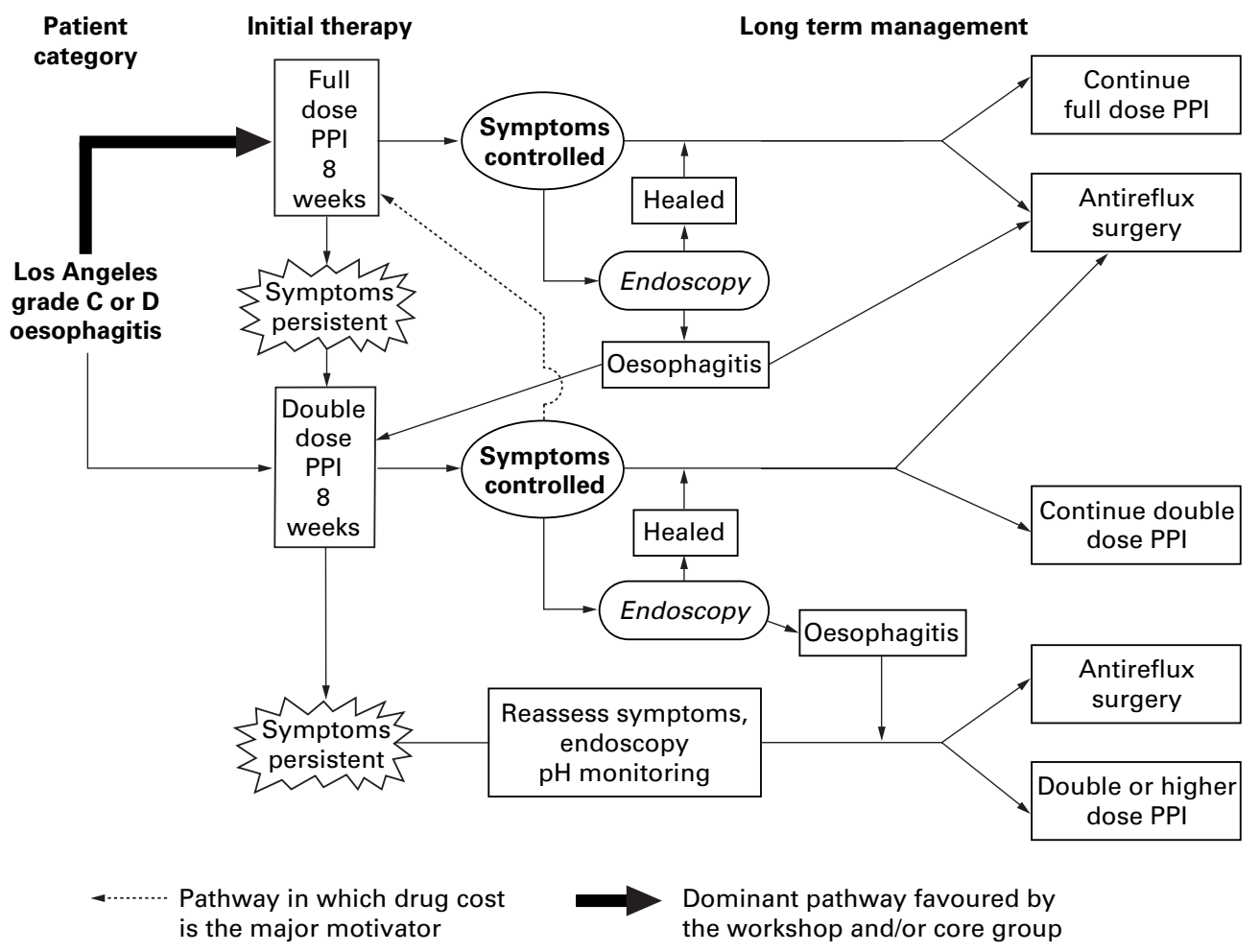

Figure 2 Major management pathways for patients known to have Los Angeles grades $C$ and $D$ oesophagitis. The pathways shown do not take into account the special (and controversial) needs for management of Barrett's oesophagus (statements 28, 29, and 53). Costs are minimised by the use of symptom response for guidance on the success or failure of therapy, rather than endoscopy (statement 62). Symptom control is defined in this setting as the reduction of symptoms to a level that does not impair health related quality of life (statements 11 and 62). For explanation of the exclusive use of proton pump inhibitors (PPI) in this patient category, see the section of text entitled "Management pathways in patients with severe oesophagitis (Los Angeles grades $C$ and D)". Anti-reflux surgery is an appropriate option at any point in the pathway, subject to patient preference and surgeon skill (statements 63-65), but especially should be considered once the patient has been evaluated by initial management strategies.

could not distinguish those with Barrett's oesophagus or severe oesophagitis from other patients with reflux disease (statements 22 and 28).

Core group: Patients with dyspepsia should be separated from those with heartburn at the initial assessment, as the primary decision pathways differ for these two symptom patterns (fig 1). Alarm symptoms are discussed later.

PLACE OF FLUOROSCOPY IN INITIAL DIAGNOSIS The Workshop agreed strongly that fluoroscopy was of very limited practical value for the diagnosis of reflux disease (statement 34). Accordingly it does not appear in the initial decision pathways in fig 1 .

WHETHER TO ENDOSCOPE EARLY

Core group: No Workshop statement considered the role of endoscopy in patients with reflux disease who present with dyspepsia, atypical symptoms or alarm symptoms such as dysphagia, weight loss or haematemesis. The core group agreed that early endoscopy was important in this minority group because of diagnostic uncertainty and the need to exclude oesophageal stricture, peptic ulcer or malignancy (fig 1).

The management of individuals who have no alarm symptoms and whose typical reflux induced symptoms were not severe enough to categorise them as having reflux disease (statements 1 and 11) was also not considered directly at the Workshop. The need to distinguish such individuals was recognised, to ensure that such patients are not managed as having reflux disease (fig 1). They are an important group which merits formal study especially to determine the prevalence of reflux oesophagitis. By default, the Workshop concluded that endoscopy was not routinely indicated in people with such mild symptoms. 53 Accepted - B: The risk of development of oesophageal adenocarcinoma in association with Barrett's oesophagus is so small in unselected individuals presenting in primary care with typical symptoms of reflux disease, that this risk should not be the primary determinant of whether endoscopy is done. Evidence - B. ${ }^{122-124}$ Barrett's oesophagus substantially complicates any discussion about the place of endoscopy in reflux disease as it is controversial, from a health economic perspective, whether it is justified to undertake surveillance for development of adenocarcinoma. ${ }^{125-127}$ The need to identify Barrett's oesophagus essentially depends on the answer to this controversy. The perspective of the patient about endoscopic surveillance will usually differ from that of a health care funding system which must balance priorities for expenditure among patients. For a more general discussion about the place of early endoscopy, see statement 54 .

Core group: This controversial statement was surprisingly strongly supported. However, the frequently stated view that the possibility of 


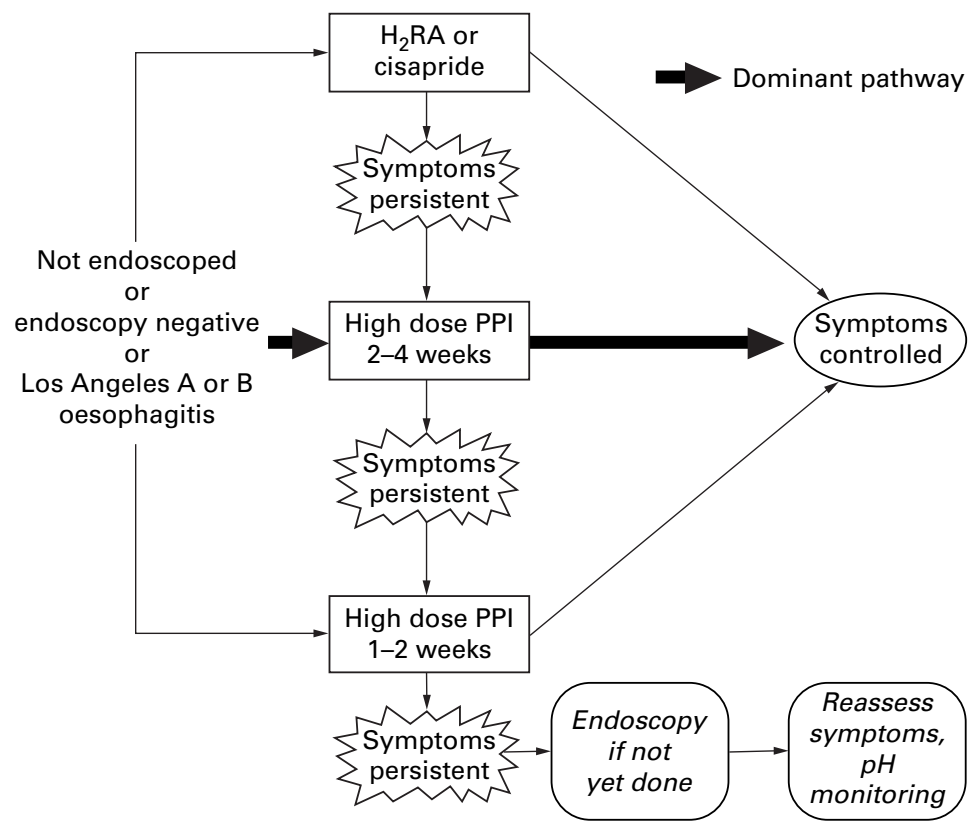

Figure 3 Major management pathways for initial management of patients who have not been endoscoped, and for endoscopy negative or mild oesophagitis patients. For the reasoning behind the use of proton pump inhibitors (PPI) as the dominant initial option, see the section of text entitled "Management pathways in not endoscoped, endoscopy negative or mild oesophagitis (Los Angeles grades A and B) patients”. Short term management is primarily determined by whether symptoms are controlled successfully by therapy. Successful control of symptoms is defined as the reduction of symptoms to a level that does not impair health related quality of life (statements 11 and 62). Failure of drug therapy, especially PPI, is an indication for endoscopy in those who have not had this previously.

Barrett's oesophagus constitutes an important indication for endoscopy in patients with chronic reflux induced symptoms is represented by the $21 \%$ of participants who rejected the statement.

54 Accepted - B: In patients without alarm symptoms who have not been endoscoped, prompt endoscopy is the best clinical strategy in those who have experienced reflux symptoms at least twice a week for at least six months. Evidence - C. ${ }^{128-130}$
It was recognised that the patient group described in the statement had a troublesome chronic problem that required long term management. The lack of direct evaluation of the utility of endoscopy was noted.

Core group: The cost and ease of access to endoscopy were variables that would have influenced voting. Though the statement was widely accepted at the Workshop, it excited vigorous discussion within the core group at its subsequent meeting. If Barrett's oesophagus is not an indication for early endoscopy (see statement 53), what were the reasons for the support given to this statement? Reasons for doing endoscopy that were raised were assessment of the presence and severity of oesophagitis to support the symptom based diagnosis, tailoring of therapy to severity of oesophagitis when present (see later), to exclude peptic ulcer or gastric cancer, and the "nonindication" of habit. The core group did not place as high a priority on early endoscopy as the Workshop group members as a whole, and figures 1 and 3 show both early endoscopy or empirical therapy without endoscopy as acceptable mainstream options. There was at least majority support for performance of endoscopy if the patient was shown to require continuous drug therapy. This is provided for in figure 4 , at the point of entry to long term drug therapy, if endoscopy had not been done previously. One view was that as endoscopy was almost inevitable, it was best to accept this and to do it early on in the course of management. Figures 3 and 4 propose settings in which endoscopy may be appropriate after a period of empirical therapy. There is a need for outcomes research into the utility of endoscopy, and the risks of not doing it; such research would also need to include assessments of how

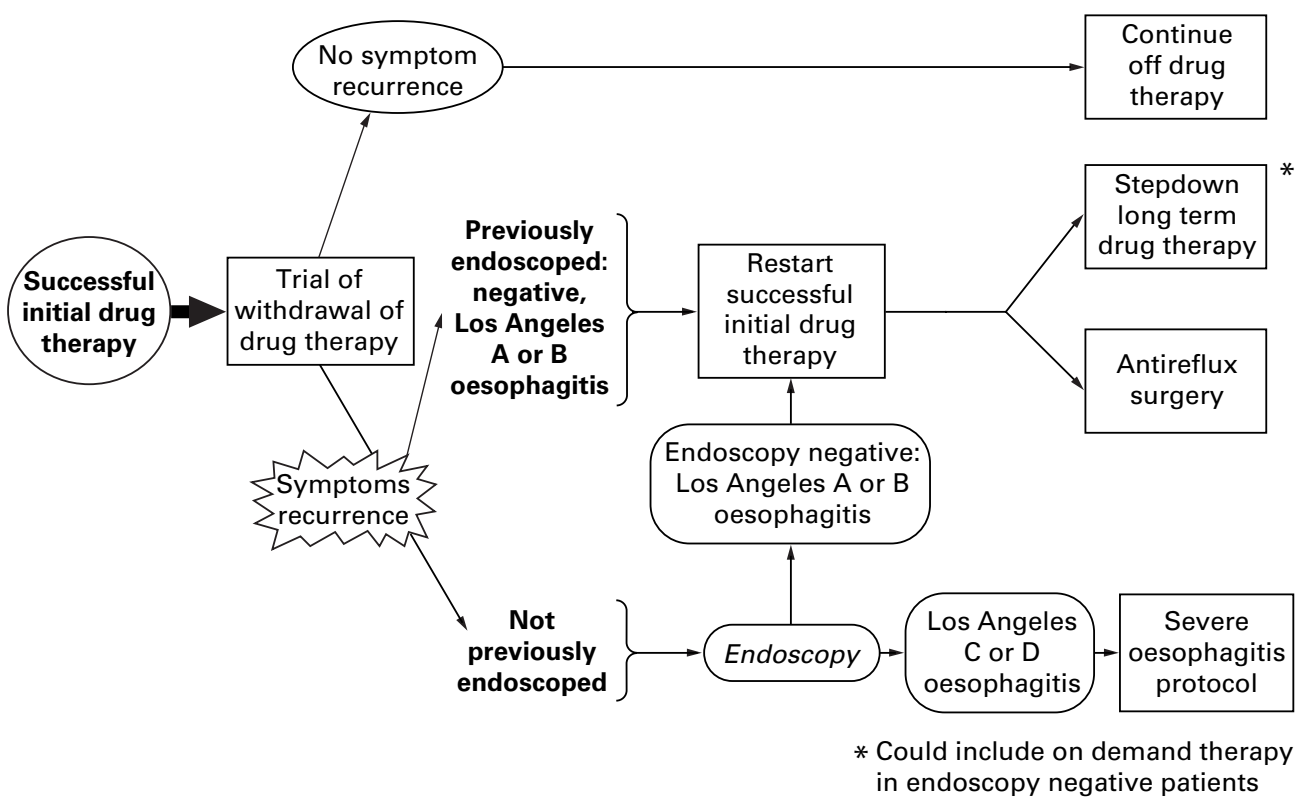

Figure 4 Major management pathways following initial drug therapy that produces successful control of symptoms in the patient groups shown. The pathways ensure that reflux disease is a recurrent problem before long term drug therapy or surgery are considered. The option of on demand therapy merits a trial in patients with endoscopy negative reflux disease, but has been studied relatively little. Non-drug measures are not included in the pathways, in deference to voting on statement 45. However, selected non-drug measures are believed to have some value (see statement 40). 
Hierarchy of the efficacy of primary drug therapies

\begin{tabular}{|l|l|}
\hline \multicolumn{2}{|c|}{ Double dose PPI } \\
\hline
\end{tabular}

Figure 5 Hierarchy of the efficacy of primary drug treatments, which should be used to guide the choice of step down (or step up) therapy. Drug costs within the applicable practice setting should also guide the choice of step down therapy. Combination $\mathrm{H}_{2}$ receptor antagonist $\left(\mathrm{H}_{2} \mathrm{RA}\right)$ and cisapride therapy are not included as primary therapies, in the light of discussion and voting on statements 51 and 52 . Because of the lack of evidence of useful benefit from double

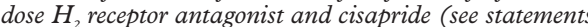
49 and 50) this option has not been included as a mainstream step. PPI, proton pump inhibitor.

early endoscopy impacts on the quality of life of patients with reflux disease (see statement 12). 55 Accepted - B: For the diagnosis of erosive reflux oesophagitis, greatest diagnostic value is obtained from endoscopy when it is done prior to the use of full dose therapy with either cisapride, $\mathrm{H}_{2}$ receptor antagonists or proton pump inhibitors. Evidence - B. ${ }^{128}$ Treatment effects could confound an important baseline assessment of oesophagitis, but treatment induced healing of oesophagitis could facilitate endoscopic recognition of Barrett's oesophagus, which may or may not be important (see statement 53). It is unclear how these effects might influence the practical value of endoscopy. The prognostic value of an initial endoscopy done in untreated patients relies on the relative stability of endoscopic grading over time (see statements 8 and 9).

Core group: If endoscopy is done after a period of treatment, the findings should be interpreted and reported in the light of the treatment that has been used.

ROLES OF A TRIAL OF THERAPY OR $\mathrm{pH}$ MONITORING

56 Accepted - A: If needed for the diagnosis of reflux disease, 24-hour oesophageal $\mathrm{pH}$ monitoring should be preceded by endoscopy and a trial of proton pump inhibitor therapy. Evidence C. ${ }^{15}{ }^{23} 76-79$ The strategy of using a trial of proton pump inhibitor therapy (see statements 35 and 36) following endoscopy was strongly supported for routine cases because it is simpler and better tolerated than oesophageal $\mathrm{pH}$ monitoring (see statements 30-32; fig 3). Some participants regarded oesophageal $\mathrm{pH}$ monitoring as most useful diagnostically in problem patients if it is done during treatment with a proton pump inhibitor.

Core group: Endoscopy should detect abnormalities unrelated to reflux disease that respond to acid suppression. If endoscopy has excluded such abnormalities, a trial of proton pump inhibitor therapy should be reasonably specific for reflux disease (see statement 36 ).
The performance of high dose, one to two week trials must be compared with that of standard dose, four week treatment periods. The use of a trial of therapy in patients who have not been endoscoped is more controversial ${ }^{92}{ }^{129}$ but it is also an approach that has considerable promise for minimisation of the costs of management of reflux disease. The decision pathways in figure 3 aim to reflect the Workshop's views of the role of a high dose, one to two week trial of proton pump inhibitor therapy.

\section{AIMS OF MANAGEMENT}

The Workshop's views on statements 10 and 11 indicate that treatment should provide sufficient control of symptoms so that, at least, they do not impair health related quality of life. This has been used as the definition of successful symptom control in figures 2, 3 and 4 .

57 Rejected - D: Minor patches of oesophageal mucosal erosion are an acceptable endoscopic outcome of therapy, since they are not associated with any known risk. Evidence - E. ${ }^{23} 26131132$ The vote demonstrated a very wide range of views, with an almost even split in the voting for rejection or support. The lack of direct evidence about the long term risks of relatively limited areas of mucosal breaks (Los Angeles grades $\mathrm{A}$ and $\mathrm{B}$ ) is highlighted by the vote on the nature of the evidence. Studies which have followed the natural history of reflux oesophagitis (see statements 8 and 9) have not reported data in sufficient detail to provide a satisfactory insight into risks in endoscopically defined subgroups of patients. Randomised clinical trials that have followed patients for periods longer than eight weeks have defined the required end point as complete healing of mucosal breaks and so give no insight into the risks of persistent mild oesophagitis. Some participants considered that acceptance of less than complete healing of mucosal breaks as an adequate outcome would be confusing, especially to non-gastroenterologists and would lead to inadequate therapy of reflux oesophagitis.

Core group: The opinions and voting of the Workshop participants differed from the core group which was less concerned about the possible long term risks of Los Angeles grades A and $\mathrm{B}$ oesophagitis. However, in deference to the Workshop, healing has been used as the aim of therapy of oesophagitis. This statement bears indirectly on whether endoscopy or symptom status alone should be used to monitor long term therapy of reflux disease (see statement 60 below).

\section{Major principles for initial and long term} medical treatment

Voting at the Workshop defined the general principle that the hierarchy of effectiveness of treatments is essentially the same for initial and long term therapy of all reflux disease patients, though there is little information about long term therapy in endoscopy negative patients. This hierarchy is an important determinant of the structure of the management decision pathways. 
Core group: At the meeting of the core group subsequent to the Workshop, it was agreed that severe oesophagitis (Los Angeles grades C and $\mathrm{D}$; fig 2) required management pathways that differed from other grades of reflux disease (figs 3 and 4). The decision pathways aim to minimise the use of endoscopy in the interests of cost effectiveness and patient comfort and convenience.

58 Accepted - A: Eradication of Helicobacter pylori infection does not heal or prevent relapse of reflux disease. Evidence - B. ${ }^{133-136}$ The vote indicates that $\bar{H}$ pylori eradication should not be considered a strategy for the management of reflux disease, in distinction to its value in patients with chronic peptic ulcer disease. This is a common area of confusion. Most people with reflux disease are $H$ pylori negative. ${ }^{136}$ When a patient with reflux disease has $H$ pylori infection, it seems that there may be a clinically relevant interaction between the two, with the possibility that reflux disease is exacerbated by $H$ pylori eradication. ${ }^{133} 135$ Data on this are, however, limited and somewhat contradictory.

Core group: In the light of the above, H pylori eradication does not appear in the decision pathway.

59 Accepted - B: For initial therapy of patients with oesophagitis, the best medical strategy is to start with a proton pump inhibitor, with subsequent trial of step down of the intensity of therapy. Evidence - C. ${ }^{57}{ }^{94} 137$ Direct evidence from formal evaluation of clinical strategies is lacking, but indirect evidence is convincing. This statement is worded in such a way that only medical outcomes were evaluated. Voting on statement 60 implies that this would also be the most cost effective strategy in many settings.

60 Accepted - B: The most effective initial therapy for reflux disease is also the most cost effective. Evidence - C. ${ }^{138-142}$ The costs of drug therapy are only part of the cost of reflux disease management. Available cost effectiveness studies support the statement as they demonstrate that the higher utilisation of medical resources that occurs as a result of failure of less effective therapies substantially outweighs any greater cost of a more effective agent for treatment periods of up to 12 months, at least in the practice settings in which the cost analyses were done.

Core group: The statement oversimplifies the issues. There are only data from patients with oesophagitis and these have significant limitations, consistent with the vote on the nature of the evidence. The costs of failure of response depend on the strategies that are used following an inadequate treatment outcome. In the models that have been formally evaluated, non-response has usually been taken as an indication for repeat endoscopy. This is probably an inappropriate strategy (see statements 61 and 62) that will drive costs excessively. The strategies illustrated in figures $2-5$ do not make such extensive use of endoscopy. Available cost analyses are also relatively short term. Given the wide spectrum of reflux disease, cost effectiveness analyses should probably focus on specific patient subgroups, such as those with mild or severe oesophagitis, or endoscopy negative patients. Cost effectiveness data should not be generalised from one region or country to another for various reasons, including differences in availability of treatment alternatives, clinical practice patterns, relative prices, and provider or institutional incentives. ${ }^{143}$ Recommendations are available which give guidance on the interpretation and application of economic studies to individual patients or practices. ${ }^{144}$

61 Accepted - B: The maintenance treatment of oesophagitis should be stepped down to the lowest dose that controls symptoms, without repeat endoscopy. Evidence - C. ${ }^{137}{ }^{145-147}$

Core group: Cost optimisation is the dominant logic behind this statement which should exclude patients with Los Angeles grades C and D oesophagitis (see later and fig 4). When correctly tailored to drug costs in a particular practice setting, the specific choice of step down will minimise drug cost, a major consideration with long term therapy. Specific downward steps are discussed later and illustrated in fig 5. Cost optimisation of long term treatment also depends on minimisation of the use of repeat endoscopy. Considerable data now exist which indicate that during maintenance therapy, sustained symptom relief is a sufficiently reliable predictor of maintained healing of oesophagitis that routine repeat endoscopy is unnecessary (see statement 62). Thus, the success of a step down in therapy can be determined with reasonable accuracy by symptom status alone. Endoscopy probably has more to offer in the follow up of patients with Los Angeles grades C and D oesophagitis as success rates of therapy are lower and the risks of oesophagitis greater.

62 Accepted - B: In more than $75 \%$ of patients with oesophagitis who present with frequent episodes of symptoms, control of heartburn to less than two episodes per week with therapy is associated with healing of oesophagitis. Evidence B. ${ }^{43} 109148$ Many clinical trials show that symptom response is a useful indicator of healing of oesophagitis. Control or complete relief of heartburn is more likely to be associated with healing of oesophagitis during therapy with a proton pump inhibitor than with an $\mathrm{H}_{2}$ receptor antagonist. ${ }^{137}$ Doubts were expressed as to whether two heartburn episodes per week was the optimal measure. The risks and benefits of using symptom response as a marker of healing need formal research.

Core group: Successful symptom control has been used in the management pathways (figs $2-4)$ as an outcome that is an acceptable indicator of healing of oesophagitis.

MANAGEMENT PATHWAYS IN PATIENTS WITH SEVERE OESOPHAGITIS (LOS ANGELES GRADES C AND D)

Core group: The special management needs of this small minority (5-10\%) patient subgroup were not specifically considered at the Workshop. Given the lack of efficacy of non-drug measures and antacids (see statement 43) and the relatively low efficacy of $\mathrm{H}_{2}$ receptor antagonists and cisapride (see statements 46, $47,51,52)$, the core group agreed that step up 
therapy was an unacceptable strategy for initial therapy in this patient group (fig 2). It was also agreed that step down therapy was inappropriate for long term care, given that two randomised trials indicate that any medical treatment other than full dose proton pump inhibitor is unlikely to prevent relapse of oesophagitis or strictures in this patient group. ${ }^{97} 149150$

MANAGEMENT PATHWAYS IN NOT ENDOSCOPED, ENDOSCOPY NEGATIVE OR MILD OESOPHAGITIS

(LOS ANGELES GRADES A AND B) PATIENTS Initial treatment

The Workshop showed a strong preference for the use of proton pump inhibitors as initial therapy in this patient group (see statement 60 ), in large part because of the hierarchy of effectiveness of available medical therapies (see statements 46-50).

Core group: Figure 3 excludes the option of lifestyle measures for initial therapy, consistent with voting on statements 37-44, and subsequent core group discussion. The relative merits of either a standard dose course of proton pump inhibitor given for four weeks, or a one to two week trial of treatment at higher dose were not considered in detail by the Workshop or the core group subsequently. The merits of these two approaches need to be formally compared in specific patient subgroups.

\section{Long term treatment}

In the case of long term treatment in patients other than those with severe oesophagitis, the Workshop discussions and voting gave substantial guidance for construction of the management pathways shown in figures 4 and 5 (see statements 43, 45-52). Half dose proton pump inhibitor therapy was recognised as an attractive long term treatment in settings where this is substantially lower in cost than full dose proton pump inhibitor. Step down therapy was strongly supported as a cost minimisation measure in this patient group (see statements 59 and 61).

Core group: Figure 3 includes a trial of withdrawal of drug therapy after successful initial treatment with either a proton pump inhibitor, an $\mathrm{H}_{2}$ receptor antagonist or cisapride. This strategy was not considered by the Workshop. There are conflicting data about relapse rates of symptoms and oesophagitis in patients with Los Angeles grades A and B oesophagitis after withdrawal of successful initial therapy. Some studies have shown relapse rates of only around $50 \%$ over six months, others $80-90 \% .^{45} 151-153$ Limited data on relapse in endoscopy negative patients show relapse rates with a similar range. ${ }^{45} 154$ The recommendation that a trial of withdrawal of drug therapy is justified can only be tentative, in the absence of data that have tackled this question directly. This strategy is included as it double checks that patients need continuous drug therapy.

The management pathways in figures 1 and 3 make it possible for patients to pass through to long term medical care without having had an endoscopy. The Workshop had a strong preference for early endoscopy (see statements
54 and 55). The core group was less confident that early endoscopy was universally appropriate. Figure 4 reflects the main weight of opinion which favoured endoscoping patients with classic, but no alarm symptoms in the first few months of their management if they required continuous drug therapy. Research is needed to examine objectively the gains and risks either from doing or not doing endoscopy.

The long term management options for endoscopy negative patients could reasonably include on demand therapy. There are limited data which indicate this approach is effective in many such patients. ${ }^{154}$ This is probably how many patients use therapy. Apart from patients with Los Angeles grades C and D oesophagitis, the risks of such an approach seem slight but need to be researched. In view of the Workshop vote on statement 57 , on demand therapy has not been included as an option for patients with Los Angeles grades A and B oesophagitis.

PLACE OF ANTI-REFLUX SURGERY

63 Accepted - B: The best reported long term (five years) results of anti-reflux surgery are equivalent to those achieved with proton pump inhibitors. Evidence - B. ${ }^{155-157}$ Substantially more data exist on the efficacy of drug therapy of reflux oesophagitis for up to one year of therapy than for anti-reflux surgery, but at five years this is reversed, with more being known about the efficacy of surgery. It was agreed that laparoscopic surgery had improved patient acceptance of anti-reflux surgery. Available published comparisons of anti-reflux surgery and drug therapy do not compare current state-of-the-art approaches for both modalities.

64 Accepted - A: The short and long term outcomes of anti-reflux surgery are highly dependent on the experience and skill of the surgeon. Evidence - B. ${ }^{158-161}$ This statement was strongly accepted, not only on the basis of the widespread clinical experience of participants, but also because of wide variations in reported efficacy in the literature, and documentation of a significant learning curve for surgeons doing laparoscopic anti-reflux surgery. ${ }^{159} 161$

65 Rejected - D: Long term medical therapy with a proton pump inhibitor is cost effective treatment for erosive reflux disease compared to laparoscopic fundoplication. The results of prospective trials, which are currently in progress, are needed to determine whether this is the case. However, both the costs of surgery and drug therapy change relatively rapidly and differ substantially in different countries and practice settings. Discussion of the statement suggested that it was rejected mainly on the grounds that the choice between medical and surgical therapy for reflux disease was much more a matter of patient preference than of economic considerations. The skill and experience of available surgeons was also recognised as a very important factor that should guide patient preference (see statement 64).

Core group: The Workshop discussion and voting did not concentrate adequately on the issue raised by the statement. Prospective trials are needed to evaluate the statement 
adequately. The statement has been tested in a decision analysis. ${ }^{162}$ Results were sensitive to the costs of medication and surgery, both of which vary widely across regions and countries. The time frame of observation was critical, as the costs of long term medical management in the available study became equivalent to surgery after 10 years. ${ }^{162}$ The analysis recognised the importance of surgical skill, and used the best available results of surgical efficacy, morbidity, and mortality rates. Such results may well not be achieved in routine clinical practice.

\section{Conclusions}

Several factors have caused a revolution in the understanding of gastro-oesophageal reflux disease over the past 20 years. These include the development and wide use of flexible endoscopes, monitoring of luminal $\mathrm{pH}$ and bilirubin concentrations, evolution of methods of assessment of oesophageal motility, and the availability of increasingly effective and more acceptable medical and surgical therapies. This revolution is distinct from the simultaneous recognition of $H$ pylori infection as the primary factor in the pathogenesis of chronic peptic ulcer.

The review of knowledge relevant to good management strategies for reflux disease undertaken at the Genval Workshop has highlighted important needs for research. There are substantial gaps in our understanding of how evaluation of symptom patterns can be best used to improve the efficacy of management and minimise the costs. The timing, roles and benefits of endoscopy need more critical evaluation, not only in patients with Barrett's oesophagus, but also in the majority of patients with reflux disease who do not have this complication. Strategies for cost effective use of both medical and surgical therapy must also be better researched in a way that takes into account the full cost of management, matching this to the benefits experienced by the patient from different therapies.

The Workshop was supported by an educational grant from Astra.

Tim Robinson and Esther Breed are thanked for their substantial contributions to the drafting of this manuscript. Richard Holloway gave considerable assistance with the references.

Other members of the Genval Workshop Group: Lars Agréus Other members of the Genval Workshop Group: Lars Agreus
(Oregrund, Sweden); David Armstrong (Hamilton, Ontario, Canada); Gil Barbezat (Salford, UK); John Calam (London, Canada); Gil Barbezat (Salford, UK); John Calam (London, (München, Germany); Ken De Vault (Jacksonville, Florida, (München, Germany); Ken De Vault (Jacksonville, Florida, USA); Jean Paul Galmiche (Nantes, France); Richard Holloway (Adelaide, Australia); Michio Hongo (Sendai, Japan); Jürgen Hotz (Celle, Germany); Terje Johannessen (Trondheim, Norway); Folke Johnsson (Lund, Sweden); Hans-Rudolf Koelz
(Zürich, Switzerland); S K Lam (Hong Kong); Mark Lane (Zürich, Switzerland); S K Lam (Hong Kong); Mark Lane
(Auckland, New Zealand); Lars Lundell (Göteborg, Sweden); Peter Malfertheiner (Magdeburg, Germany); Paul Moayyed (Leeds, UK); Wolfgang Rösch (Frankfurt, Germany); Marc Silverstein (Charleston, South Carolina, USA); Amnon Sonnenberg (Albuquerque, New Mexico, USA); Vincenzo Stanghellini (Bologna, Italy); Ian Wallace (Auckland, New Zealand); Anthony Watson (London, UK; Yin Thing Phee (Selango Darul Ehsan, Malaysia).

1 Dimenäs E. Methodological aspects of evaluation of quality of life in upper gastrointestinal diseases. Scand $\mathcal{F}$ Gastroenterol 1993;28(suppl 199):18-21.

2 Glise H, Hallerbäck B, Johansson B. Quality-of-life assessments in the evaluation of gastroesophageal reflux assessments in the evaluation of gastroesophageal reflux
and peptic ulcer disease before, during and after treatment. and peptic ulcer disease before, during and after trea
Scand $\mathscr{f}$ Gastroenterol 1995;30(suppl 208):133-5.
3 Rush DR, Stelmach WJ, Young TL, et al. Clinical effectiveness and quality of life with ranitidine vs placebo in gastroesophageal reflux disease patients: a clinical experience network (CEN) study. F Fam Pract 1995;41:126-36.

4 Glise $\mathrm{H}$, Wiklund I. Measurement of the impact of heartburn and dyspepsia on quality of life. Aliment Pharmacol Ther 1997;11(suppl 2):73-7.

5 Lydeard S, Jones R. Factors affecting the decision to consult with dyspepsia: comparison of consulters and nonconsulters. $\mathcal{F}$ Royal Coll Gen Pract 1989;39:495-8.

6 Bytzer P, Havelund T, Møller Hansen J. Interobserver variation in the endoscopic diagnosis of reflux esophagitis. Scand $\mathcal{F}$ Gastroenterol 1993;28:119-25.

7 Armstrong D, Bennett JR, Blum AL, et al. The endoscopic assessment of esophagitis: a progress report on observer agreement. Gastroenterology 1996;111:85-92.

8 Lundell L, Dent J, Bennett JR, et al. Endoscopic assessment of esophagitis - clinical and functional correlates and further validation of the Los Angeles classification. Submitted.

9 Robertson DAF, Aldersley MA, Shepherd $\mathrm{H}$, et al. $\mathrm{H}_{2}$ antagonists in the treatment of reflux oesophagitis: can physiological studies predict the response? Gut 1987;28: 946-9.

10 Wiener GJ, Richter JE, Copper JB, et al. The symptom index: a clinically important parameter of ambulatory 24-hour esophageal pH monitoring. Am $\mathcal{f}$ Gastroenterol 1988;83:358-61.

11 Breumelhof R, Smout AJPM. The symptom sensitivity index: a valuable additional parameter in 24-hour esophageal pH recording. Am f Gastroenterol 1991;86:160-4.

12 Johnston BT, Collins JS, McFarland RJ, et al. Are esophageal symptoms reflux-related? A study of different scoring systems in a cohort of patients with heartburn. $A m$ scoring systems in a cohort of patien
$\mathcal{f}$ Gastroenterol $1994 ; 89: 497-502$

13 Masclee AAM, de Best CAM, de Graaf R, et al. Ambulatory 24-hour pH-metry in the diagnosis of gastroesophageal reflux disease - determination of criteria and relation to endoscopy. Scand f Gastroenterol 1990;25:225-30.

14 Schindlbeck NE, Heinrich C, Konig A, et al. Optimal thresholds, sensitivity, and specificity of long-term $\mathrm{pH}$ metry for the detection of gastroesophageal reflux disease. Gastroenterology 1987;93:85-90.

15 Shi G, des Varannes SB, Scarpignato C, et al. Reflux related symptoms in patients with normal oesophageal exposure to acid Gut 1995;37:457-64.

16 Watson RG, Tham TC, Johnston BT, et al. Double-blind cross-over placebo controlled study of omeprazole in the treatment of patients with reflux symptoms and physiological levels of acid reflux - the "sensitive oesophagus." Gut 1997;40:587-90.

17 Kjellin A, Ramel S, Rössner S, et al. Gastroesophageal reflux in obese patients is not reduced by weight reduction. Scand 7 Gastroenterol 1996;31:1047-51.

18 Boeckxstaens GY, Tytgat GNJ. Pathophysiology, diagnosis, and treatment of gastroesophageal reflux disease. Curr Opin Gastroenterol 1996;12:365-72.

19 Sontag SJ. Rolling review: gastro-oesophageal reflux disease. Aliment Pharmacol Ther 1993;7:293-312.

20 Waring JP, Eastwood TF, Austin JM, et al. The immediate effects of cessation of cigarette smoking on gastroesophageal reflux. Am $\mathcal{F}$ Gastroenterol 1989;84:1076-8.

21 Kahrilas PJ. Cigarette smoking and gastroesophageal reflux disease. Dig Dis 1992;10:61-71.

22 Becker DJ, Sinclair J, Castell DO, et al. A comparison of high and low fat meals on postprandial esophageal acid exposure. Am 7 Gastroenterol 1989;84:782-6.

23 Schindlbeck NE, Klauser AG, Berghammer G, et al. Three year follow up of patients with gastro-oesophageal reflux disease. Gut 1992;33:1016-19.

24 Isolauri J, Luostarinen $M$, Isolauri E, et al. Natural course of gastroesophageal reflux disease: 17-22 year follow-up of 60 patients. Am f Gastroenterol 1997;92:37-41.

25 Ollyo JB, Monnier P, Fontolliet C, et al. The natural history, prevalence and incidence of reflux oesophagitis. Gullet 1993;3(suppl):3-10.

26 Kuster E, Ros E, Toledo-Pimentel V, et al. Predictive factors of the long-term outcome in gastro-oesophageal reflux disease: six-year follow-up of 107 patients. Gut 1994;35:814

27 Ben Rejeb M, Bouché O, Zeitoun P. Study of 47 consecutive patients with peptic esophageal stricture compared with 3880 cases of reflux esophagitis. Dig Dis Sci 1992;37:7336.

28 Spechler SJ. Epidemiology and natural history of gastrooesophageal reflux disease. Digestion 1992;51(suppl 1): $24-9$.

29 Glise H. Quality of life and cost of therapy in reflux disease. Scand $\mathcal{F}$ Gastroenterol 1995;30(suppl 210):38-42.

30 Dimenäs E, Carlsson G, Glise H, et al. Relevance of norm values as part of the documentation of quality-of-life instruments for use in upper gastrointestinal disease. Scand $\mathcal{f}$ Gastroenterol 1996;31 (suppl 221):8-13.

31 Lind T, Havelund T, Carlsson R, et al. The effect of omeprazole (OME) $20 \mathrm{mg}$ and $10 \mathrm{mg}$ daily on heartburn in patients with endoscopy negative reflux disease (ENRD) [abstract]. Gastroenterology 1995;108:A151

32 Lind $\mathrm{T}$, Havelund $\mathrm{T}$, Glise $\mathrm{H}$, et al. Omeprazole (OME) improves quality of life (QoL) in patients with endoscopy negative reflux disease (ENRD) [abstract]. Gastroenterology 1995;108(suppl 4):A151. 
33 McDougall NI, Johnston BT, Kee F, et al. Natural history of reflux oesophagitis: a 10-year follow-up of its effect on patient symptomatology and quality of life. Gut 1996;38

34 Stacey JH, Miocevich ML, Sacks GE. The effect of ranitidine (as effervescent tablets) on the quality of life of GORD patients. Br F Clin Pract 1996;50:190-4.

35 Johannessen T, Petersen H, Kleveland PM, et al. The predictive value of history in dyspepsia. Scand $\mathcal{F}$ Gastroenterol 1990;25:689-97.

36 Glise H, Hallerback B, Johansson B. Quality-of-life assessments in evaluation of laparoscopic Rosetti fundoplication. Surg Endosc 1995; 9:183-9.

37 Johnston BT, Gunning J, Lewis SA. Health care seeking by heartburn sufferers is associated with psychosocial factors. Am $\mathcal{F}$ Gastroenterol 1996;91:2500-4.

38 Glise H, Hallerbäck B, Wiklund I. Quality of life: a reflection of symptoms and concerns. Scand $\mathcal{F}$ Gastroenterol 1996; 32(suppl 221):14-17.

39 Lucock MP, Morley S, White C, et al. Responses of consecutive patients to reassurance after gastroscopy: results of self administered questionnaire survey. BMF 1997;315:572-5.

40 Wiklund I, Glise H, Jerndal P, et al. Endoscopy has a positive impact on quality of life in dyspepsia. Gastrointest Endosc 1998;47:449-54.

41 Bytzer P, Hansen, JM, Schaffalitzky de Muckadell OB. Empirical $\mathrm{H}_{2}$-blocker therapy or prompt endoscopy in management of dyspepsia. Lancet 1994;343:811-16.

42 Klauser AG, Schindlbeck NE, Müller-Lissner SA. Symptoms in gastro-oesophageal reflux disease. Lancet 1990; toms in gas:

43 Carlsson R, Frison L, Lundell L, et al. Relationship between symptoms, endoscopic findings and treatment outcome in reflux esophagitis [abstract]. Gastroenterology 1996;110: A77.

44 Galmiche J-P, Barthelemy P, Hamelin B. Treating the symptoms of gastro-oesophageal reflux disease: a double-blind comparison of omeprazole and cisapride. Aliment Pharmacol Ther 1997;11:765-73.

45 Carlsson R, Dent J, Watts R, et al. Gastro-oesophageal reflux disease (GORD) in primary care - an international study of different treatment strategies with omeprazole. Eur $f$ Gastroenterol Hepatol 1998;10:119-24.

46 Lind T, Havelund T, Carlsson R, et al. Heartburn without oesophagitis: efficacy of omeprazole therapy and features determining therapeutic response. Scand 7 Gastroenterol 1997;32:974-9.

47 Small PK, Loudon MA, Waldron B, et al. Importance of reflux symptoms in functional dyspepsia. Gut 1995;36: $189-92$.

48 Locke GR, Talley NJ, Weaver AL, et al. A new questionnaire for gastroesophageal reflux disease. Mayo Clin Proc for gastroesophage.

49 Carlsson R, Dent J, Bolling-Sternevald E, et al. The usefulness of a structured questionnaire in the assessment of symptomatic gastroesophageal reflux disease. Scand $\mathcal{f}$ Gastroenterol 1998;33:1023-9.

50 Carlsson R, Bolling E, Jerndal P, et al. Factors predicting response to omeprazole treatment in patients with functional dyspepsia [abstract]. Gastroenterology 1996;110: A76.

51 Talley NJ, Colin-Jones D, Koch KL, et al. Functional dyspepsia: a classification with guidelines for diagnosis and management Gastroenterol Int 1991:4:145-60.

52 Johnsson F, Roth Y, Damgaard-Pedersen N-E, et al. Cimetidine improves GERD symptoms in patients selected by a validated GERD questionnaire. Aliment Pharmacol Ther 1993;7:81-6.

53 Robertson DAF, Aldersley MA, Shepherd H, et al. Patterns of acid reflux in complicated oesophagitis. Gut 1987;28: of acid $1484-8$.

54 Johnsson L, Adloum W, Johnsson F, et al. Timing of reflux symptoms and esophageal acid exposure. Gullet 1992;2:58 62.

55 Gudmundsson K, Johnsson F, Joelsson B. The time pattern of gastroesophageal reflux. Scand F Gastroenterol 1988;23: $75-9$.

56 Mann SG, Murakami A, McCarroll K, et al. Low dose famotidine in the prevention of sleep disturbance caused by heartburn after an evening meal. Aliment Pharmacol Ther 1995;9:395-401.

57 Venables T, Newland R, Patel AC, et al. Omeprazole 10 milligrams once daily, omeprazole 20 milligrams once daily, or ranitidine 150 milligrams twice daily, evaluated as initial therapy for the relief of symptoms of gastro-oesophageal therapy for the relief of symptoms of gastro-oesophageal reflux disease in

58 Green JRB. Is there such an entity as mild oesophagitis? Eur f Clin Res 1993;4:29-34.

59 Smout AJPM. Endoscopy-negative acid reflux disese. Aliment Pharmacol Ther 1997;11(suppl 2):81-5.

60 Locke GR, Talley NJ, Fett SL, et al. Prevalence and clinica spectrum of gastroesophageal reflux: a population-based study in Olmsted Country, Minnesota. Gastroenterology 1997;112:1448-56

61 Lööf L, Götell P, Elfberg B. The incidence of reflux oesophagitis. Scand $\mathcal{F}$ Gastroenterol 1993;28:113-18.

62 Jones RH, Hungin APS, Phillips J, et al. Gastro-oesophageal reflux disease in primary care in Europe: clinical presentation and endoscopic findings. Eur f Gen Pract 1995;1:149tion

63 Robinson M, Earnest D, Maton PN, et al. Frequent heartburn symptoms should not be ignored in subjects who self-treat with antacids [abstract]. Gastroenterology 1996; 10:A241.

64 Gustavsson S, Bergström R, Erwall C, et al. Reflux esophagitis: assessment of therapy effects and observer variation by video documentation of endoscopy findings. Scand $\mathcal{F}$ Gastroenterol 1987;22:585-91.

65 Johnsson F, Joelsson B, Gudmundsson K, et al. Symptoms and endoscopic findings in the diagnosis of gastroesophageal reflux disease. Scand F Gastroenterol 1987;22:714-18.

66 Schindlbeck NE, Wiebecke B, Klauser AG, et al. Diagnostic value of histology in nonerosive gastro-oesophageal reflux disease. Gut 1996;39:151-4.

67 Ismail-Beigi F, Horton PF, Pope CE. Histological consequences of gastro

68 Collins BJ, Elliott H, Sloan JM, et al. Oesophageal histology in reflux esophagitis. $\mathcal{F}$ Clin Pathol 1985;38:1265-72.

69 Armstrong D, Emde C, Inauen W, et al. Diagnostic assessment of gastroesophageal reflux disease: what is possible vs. what is practical? Hepatogastroenterology 1992; 39(suppl 1):3-13.

70 Spechler SJ, Goyal RJ. The columnar-lined esophagus, intestinal metaplasia, and Norman Barrett. Gastroenterology 1996;110:614-21.

71 Nandurkar S, Talley NJ, Martin CJ, et al. Short segment Barrett's oesophagus: prevalence, diagnosis and associations. Gut 1997;40:710-15.

72 Spechler SJ. Short and ultrashort Barrett's esophagus - what does it mean? Semin Gastrointest Dis 1997;8:59-67.

73 Spechler SJ, Zeroogian JMZ, Antonioli DA, et al. Prevalence of metaplasia at the gastro-oesophageal junction. Lancet 1994;344:1533-6.

74 Weston AP, Krmpotich PT, Cherian R, et al. Prospective long-term endoscopic and histological follow-up of short segment Barrett's esophagus: comparison with traditional long segment Barrett's esophagus. Am f Gastroenterol 1997; 92:407-13.

75 Ghillebert G, Demeyere AM, Janssens J, et al. How well can quantitative 24-hour intraesophageal $\mathrm{pH}$ monitoring distinguish various degrees of reflux disease? Dig Dis Sci 1995; 40:1317-24

76 Kahrilas PJ, Quigley EMM. Clinical esophageal pH recording: a technical review for practice guideline development. Gastroenterology 1996;110:1982-96.

77 Klauser AG, Heinrich C, Schindlbeck NE, et al. Is ong-term esophageal $\mathrm{pH}$ monitoring of clinical value? $\mathrm{Am}$ 7 Gastroenterol 1989;84:362-6.

78 Olden K, Triadafilopoulos G. Failure of initial 24-hour esophageal $\mathrm{pH}$ monitoring to predict refractoriness and intractability in reflux esophagitis. Am f Gastroenterol 1991; 86:1141-6.

79 Quigley EMM. 24-hour pH monitoring for gastroesophageal reflux disease: already standard but not yet gold? $A m \mathcal{F}$ Gastroenterol 1992;87:1071-5.

80 Johnsson F, Joelsson B. Reproducibility of ambulatory oesophageal $\mathrm{pH}$ monitoring. Gut 1988;29:886-9.

81 Wiener GJ, Morgan TM, Copper JB, et al. Ambulatory 24-hour esophageal $\mathrm{pH}$ monitoring. Reproducibility and variability of pH parameters. Dig Dis Sci 1988;33:1127-33.

82 Orr WC. The physiology and philosophy of cause and effect. Gastroenterology 1994;107:1898-901.

83 Weusten BLAM, Roelofs JM, Akkermans LM, et al. The symptom-association probability: an improved method for symptom analysis of 24-hour esophageal $\mathrm{pH}$ data. Gastroenterology 1994;107:1741-5.

84 Weusten BLAM, Akkermans LMA, Vanberg-Henegouwen $\mathrm{GP}$, et al. Symptom perception in gastroesophageal reflux disease is dependent on spatiotemporal reflux characterisdisease is dependent on spatiotemporal
tics. Gastroenterology 1995;108:1739-44.

85 Cohen S, Harris LD. Does hiatal hernia affect competence of the gastresophageal sphincter? N Engl F Med 1971;284

86 Sloan S, Rademaker AW, Kahrilas PJ. Determinants of gastroesophageal junction incompetence: Hiatal hernia, lower esophageal sphincter, or both? Ann Intern Med 1992;117: 977-82.

87 Petersen $\mathrm{H}$. The clinical significance of hiatus hernia. Scand f Gastroenterol 1995;(suppl 211):19-20.

88 Ott DJ, Glauser SJ, Ledbetter MS, et al. Association of hiatal hernia and gastroesophageal reflux: correlation between presence and size of hiatal hernia and 24-hour $\mathrm{pH}$ monitoring of the esophagus. AfR Am $\mathcal{F}$ Roentgenol 1995;165:557-9.

89 Johnston BT, Troshinsky MB, Castell JA, et al. Comparison of barium radiology with esophageal $\mathrm{pH}$ monitoring in the diagnosis of gastroesophageal reflux disease. Am 7 Gastroenterol 1996;91:1181-5.

90 Schindlbeck NE, Klauser AG, Voderholzer WA, et al. Empiric therapy for gastroesophageal reflux disease. Arch Intern Med 1995;155:1808-12.

91 Johnsson F, Weywadt L, Solhaug JH, et al. One week omeprazole treatment in the diagnosis of gastroeesophageal reflux disease. Scand F Gastroenterol 1998;33: $15-20$.

92 Brun J, Bengtsson L, Sörngärd H. Diagnostic test and treatment of acid related GERD in a general practice population [abstract]. Gut 1997;41(suppl 3):A63.

93 Schenk BE, Kuipers EJ, Klinkenberg-Knol EC, et al. Omeprazole as a diagnostic tool in gastro-esophageal reflux disease. Am f Gastroenterol 1997;92:1997-2000.

94 Chiba N, De Gara CJ, Wilkinson JM, et al. Speed of healing and symptom relief in grade II to IV gastroesophageal $1798-810$. 
95 Fass R, Fennerty B, Yalam JM, et al. Evaluation of the "omeprazole test" in patients with typical symptoms of gastroesophageal reflux disea
enterology 1997;112:A114

96 Holloway RH, Dent J, Narielvala F, et al. Relation between oesophageal acid exposure and healing of oesophagitis with omeprazole in patients with severe reflux oesophagitis. Gut 1996;38:649-54.

97 Klinkenberg-Knol EC, Festen H, Jansen J, et al. Long-term treatment with omeprazole for refractory reflux esophagitis: efficacy and safety. Ann Intern Med 1994;121: esophagiti $161-7$.

98 Kitchin LI, Castell DO. Rationale and efficacy of conservative therapy for gastroesophageal reflux disease. Arch Intern Med 1991;151:448-54.

99 Shay SS, Conwell DL, Mehindru V, et al. The effect of posture on gastroesophageal reflux event frequency and composition during fasting. Am f Gastroenterol 1996;91: 54-60.

100 Johnson LF, DeMeester TR. Evaluation of elevation of the head of the bed, Bethanechol, and antacid foam tablets on gastroesophageal reflux. Dig Dis Sci 1981;26: 673-80.

101 Harvey RF, Gordon PC, Hadley N et al. Effects of sleeping with the bed-head raised and of ranitidine in patients with severe peptic oesophagitis. Lancet 1987;ii:1200-3.

102 Pehl C, Pfeiffer A, Wendl B, et al. The effect of decaffeination of coffee on gastro-oesophageal reflux in patients with reflux disease. Aliment Pharmacol The 1997;11:483-6.

103 Murphy DW, Castell DO. Chocolate and heartburn: evidence of increased esophageal acid exposure after chocolate ingestion. Am f Gastroenterol 1988;83:6336.

104 Allen ML, Mellow MH, Robinson MG, et al. The effect of raw onions on acid reflux and reflux symptoms. Am $\mathcal{F}$ Gastroenterol 1990;85:377-80.

105 Graham DY, Patterson DJ. Double-blind comparison of liquid antacid and placebo in the treatment of symptomatic reflux esophagitis. Dig Dis Sci 1983;28:559-63.

106 Graham DY, Lanza F, Dorsch ER. Symptomatic reflux esophagitis: a double-blind controlled comparison of antacids and alginate. Curr Ther Res 1977;22:653-8.

107 Dent J. Heartburn - lifting the veil of mythology. Med $\mathcal{F}$ Aust 1992;157:336-7.

108 Simon TJ, Berlin RG, Gardner AH, et al. Self-directed treatment of intermittent heartburn: a randomized, multiacid and low doses of an $\mathrm{H}_{2}$-receptor antagonist (famotiacid and low doses of an $\mathrm{H}_{2}$-recept
dine). Am $\mathcal{F}$ Ther 1995;2:304-13.

109 Vigneri S, Termini R, Leandro G, et al. A comparison of five maintenance therapies for reflux esophagitis. $N$ Engl $\mathscr{f}$ Med 1995;333:1106-10.

110 Gough AL, Long RG, Cooper BT, et al. Lansoprazole versus ranitidine in the maintenance treatment of reflux oesophagitis. Aliment Pharmacol Ther 1996;10:52939.

111 Bate CM, Griffin SM, Keeling PWN, et al. Reflux symptom relief with omeprazole in patients without unequivocal oesophagitis. Aliment Pharmacol Ther 1996;10: unequivoca.

112 Armstrong D. The clinical usefulness of prokinetic agents in gastro-oesophageal reflux disease. In: Lundell L, ed. The management of gastroesophageal reflux disease. London: Science Press, 1997:45-54.

113 Reynolds JC. Individualized acute treatment strategies for gastroesophageal reflux disease. Scand $\mathcal{f}$ Gastroentero 1995;30(suppl 213):17-24.

114 Wesdorp ICE, Dekker W, Festen HPM. Efficacy of famotidine $20 \mathrm{mg}$ twice a day versus $40 \mathrm{mg}$ twice a day in the treatment of erosive or ulcerative reflux esophagitis. Dig $D i$ s Sci 1993;38:2287-93.

115 Simon TJ, Berenson MM, Berlin RG, et al. Randomized, placebo-controlled comparison of famotidine $20 \mathrm{mg}$ b.d. or
$40 \mathrm{mg}$ b.d. in patients with erosive oesophagitis. Aliment $40 \mathrm{mg}$ b.d. in patients with

116 Tytgat GNJ, Nicolai JJ, Reman FC. Efficacy of different doses of cimetidine in the treatment of reflux esophagitis. A review of three large, double-blind, controlled trials. Gastroenterology 1990;99:629-34.

117 Johnson N, Boyd E, Mills J, et al. Acute treatment of reflux oesophagitis: a multi-centre trial to compare $150 \mathrm{mg}$ ranitidine b.d with $300 \mathrm{gm}$ ranitidine $\mathrm{q}$.d.s. Aliment Pharmacol Ther 1989;3:258-66.

118 Geldof H, Hazelhoff B, Otten MH. Two different dose regimens of cisapride in the treatment of reflux regimens of cisapride in the treatment of reflux Aliment Pharmacol Ther 1993;7:409-15.

119 van Outryve M, Vanderlinden I, Dedullen G, et al. Dose-response study with cisapride in gastroesophageal reflux disease. Curr Ther Res 1988;48:408-15.

120 Ramirez B, Richter JE. Promotility drugs in the treatment of gastro-oesophageal reflux disease. Aliment Pharmaco Ther 1993;7:5-20.

121 Galmiche JP, Brandstätter G, Evreux M, et al. Combined therapy with cisapride and cimetidine in severe reflux oesophagitis: a double blind controlled trial. Gut 1988;29: 675-81.

122 Cameron AJ, Zinsmeister AR, Ballard DJ, et al. Prevalence of columnar-lined (Barrett's) esophagus - comparison of population-based clinical and autopsy findings. Gastroenterology 1990;99:918-22.
123 van der Burgh A, Dees J, Hop SCJ, et al. Oesophageal cancer is an uncommon cause of death in patients with cer is an uncommon cause of death

124 Williamson WA, Ellis FH Jr, Gibb SP, et al. Barrett's esophagus prevalence and incidence of adenocarcinoma. Arch Intern Med 1991;151:2212-16.

125 Wright TA, Gray MR, Morris AI, et al. Cost effectiveness of detecting Barrett's cancer. Gut 1996;39:574-9.

126 Grimm I, Shaheen N, Bozymski EM. Surveillance for Barrett's esophagus: are we saving lives? Gastroenterology 1997; 112:661-2.

127 Provenzale D, Kemp JA, Arora S, et al. A guide for surveillance of patients with Barrett's esophagus. Am f Gastroenterol 1994;89:670-80.

128 Ellis KK, Oehlke M, Helfand M, et al. Management of symptoms of gastroesophageal reflux disease: does endoscopy influence medical management? $A m \mathcal{F}$ Gastroenterol 1997;92:1472-4.

129 Kahrilas PJ. Treatment versus management of gastroesophageal reflux disease. Am $\mathcal{f}$ Gastroenterol 1997;92: 1959-60

130 Winters C, Spurling TJ, Chobanian SJ, et al. Barrett's esophagus: a prevalent occult complication of gastroesophageal reflux disease. Gastroenterology 1987;92:11824

131 Trimble KC, Douglas S, Pryde A, et al. Clinical characteristics and natural history of symptomatic but not excess gastroesophageal reflux. Dig Dis Sci 1995;40:1098-104.

132 Pace F, Manzionna G, Bollani S, et al. Natural history of reflux esophagitis: a 5-year follow-up [abstract]. Gastroenterology 1997;112:A249.

133 Labenz J, Blum AL, Bayerdörffer E, et al. Curing Helicobacter pylori infection in patients with duodenal ulcer may provoke reflux esophagitis. Gastroenterology 1997;112:1442-7.

134 Werdmuller BFM, Loffeld RJLF. Helicobacter pylori infection has no role in the pathogenesis of reflux esophagi-

135 Labenz J, Malfertheiner P. Helicobacter pylori in gastrooesophageal reflux disease: causal agent, independent or protective factor? Gut 1997;41:277-80.

136 Csendes A, Smok G, Cerda G, et al. Prevalence of Helicobacter pylori infection in 190 control subjects and in 236 patients with gastroesophageal reflux, erosive esophagitis or Barrett's esophagus. Diseases of the Esophagus 1997;10:3842 .

137 Carlsson R, Galmiche J-P, Dent J, et al. Prognostic factors influencing relapse of oesophagitis during maintenance therapy with antisecretory drugs: a meta-analysis of long-term omeprazole trials. Aliment Pharmacol Ther 1997; 11:473-82.

138 Bate CM, Richardson PD. A one year model for the costeffectiveness of treating reflux esophagitis. $\mathrm{Br} \mathcal{F} \mathrm{Med}$ Econ 992;2:5-11.

139 Hillman AL, Bloom BS, Fendrick AM, et al. Cost and quality effects of alternative treatments for persistent gastroesophageal reflux disease. Arch Intern Med 1992;152: $1467-72$.

140 Lindeberg G. Omeprazole vs. ranitidine in reflux oesophagitis in Sweden. Pharmacoeconomics 1994;5(suppl 3):2734.

141 Fennerty MB. Medical treatment of GERD in the managed care environment. Semin Gastrointest Dis 1997;8: $90-9$.

42 Fennerty MB. The economics of therapy of gastroesophageal reflux disease. Gastroenterol Int 1997;10:126-30.

143 Drummond W. Comparing cost effectiveness across countries. The model of acid-related disease. Pharmacoeconomics 1994;5(suppl 3):60-7.

144 O'Brien BJ, Heyland D, Richardson WS, et al. User's guide to the medical literature. XIII. How to use an article on economic analysis of clinical practice. What are the results
and will they help me in caring for patients? $f A M A$ and will they help

45 Dent J, Yeomans ND, Mackinnon M, et al. Omeprazole v ranitidine for prevention of relapse in reflux oesophagitis. A controlled double blind trial of their efficacy and safety. Gut 1994;35:590-8

146 Harris RA, Kuppermann M, Richter JE. Prevention of recurrences of erosive esophagitis: a cost-effectiveness analysis of maintenance proton pump inhibition. Am f Med 1997;102:78-88.

147 Bate CM, Booth SN, Crowe JP, et al. Omeprazole $10 \mathrm{mg}$ or $20 \mathrm{mg}$ once daily in the prevention of recurrence of reflux oesophagitis. Gut 1995;36:492-8.

148 Bardhan KD, Müller-Lissner S, Bigard MA, et al. Symptomatic gastroesophageal reflux disease (GERD): intermittent treatment (IT) with omeprazole (OM) and ranitidine (RAN) as a strategy for management [abstract]. Gastroen-
terology 1997;428:A65.

149 Marks RD, Richter JE, Rizzo J, et al. Omeprazole versus $\mathrm{H}_{2}$-receptor antagonists in treating patients with peptic stricture and esophagitis. Gastroenterology 1994;106:90715.

150 Smith PM, Kerr GD, Cockel R, et al. A comparison of omeprazole and ranitidine in prevention of recurrence of benign esophageal stricture. Gastroenterology 1994;107: $1312-18$.

151 Tytgat GNJ. Long-term therapy for reflux esophagitis. $N$ Engl f Med 1995;333:1148-50.

152 Tytgat GNJ, Blum AL, Verlinden M. Prognostic factors for relapse and maintenance treatment with cisapride in gastro-oesophageal reflux disease. Aliment Pharmacol Ther
1995;9:271-80. 
153 Hetzel DJ, Dent J, Reed WD, et al. Healing and relapse of severe peptic esophagitis after treatment with omeprazole. Gastroenterology 1988;95:903-12.

154 Lundell L. New information relevant to long-term management of endoscopy-negative reflux disease. Aliment Pharmacol Ther 1997;11(suppl 2):93-8.

155 Lundell L, Abrahamsson H, Ruth M, et al. Long-term results of a prospective randomized comparison of total fundic wrap (Nissen-Rossetti) or semifundoplication (Toupet) for gastro-oesophageal reflux. Br F Surg 1996;83:830-5.

156 Johansson J, Johnsson F, Joelsson B, et al. Outcome 5 years after $360^{\circ}$ fundoplication for gastro-oesophageal reflux disease. Br 7 Surg 1993;80:46-9.

157 Watson A, Jenkinson LR, Ball CS, et al. A more physiological alternative to total fundoplication for the surgical correction of resistant gastro-oesophageal reflux. $\mathrm{Br} \mathcal{F}$ Surg 1991; 78:1088-94.
158 Orringer MB, Skinner DB, Belsey RHR. Long-term results of the Mark IV operation for hiatal hernia and
analyses of recurrences and their treatment. 7 Thoracic Caranalyses of recurrences and their
diovasc Surg 1972;63:25-33.

159 Watson DI, Baigrie RJ, Jamieson GG. A learning curve for laparoscopic fundoplication. Ann Surg 1996;224:198203.

60 Watson DI, Jamieson GG, Baigrie RJ, et al. Laparoscopic surgery for gastro-oesophageal reflux: beyond the learning curve. Br F Surg 1996;83:1284-7.

161 Perdikis G, Hinder RH, Lund RJ, et al. Laparoscopic Nissen fundoplication: where do we stand? Surg Laparosc Endosc 1997;1:17-21.

162 Heudebert GR, Marks R, Wilcox CM, et al. Choice of ong-term strategy for the management of patients with severe esophagitis: a cost utility analysis. Gastroenterology 1997;112:1078-86. 